\title{
LA BUENA ADMINISTRACIÓN COMO PRINCIPIO Y COMO DERECHO FUNDAMENTAL EN EUROPA*
}

\author{
GOOD ADMINISTRATION AS A PRINCIPLE \\ AND FUNDAMENTAL RIGHT IN EUROPE
}

\author{
BOA ADMINISTRAÇÃO COMO UM PRINCÍPIO \\ E COMO DIREITO FUNDAMENTAL NA EUROPA
}

\section{RESUMEN}

El derecho fundamental a la buena administración, tal y como está redactado en el artículo 41 de la Carta de los Derechos Fundamentales de la Unión Europea de diciembre de 2000, trae consigo un replanteamiento del derecho administrativo en su conjunto. Ahora, desde la centralidad del ciudadano y desde su participación activa en la conformación de los intereses generales, el derecho administrativo y sus principales categorías deben ser nuevamente formulados puesto que ahora la relevancia de los derechos fundamentales de la persona sugiere nuevas formas de comprender el sistema del derecho administrativo.

\footnotetext{
* El presente trabajo es un artículo de reflexión acerca del impacto que está produciendo en el sistema del Derecho Administrativo la centralidad de la dignidad del ser humano y, sobre todo, la buena administración entendida como principio jurídico y como derecho fundamental de la persona.

a. Doctor en derecho por la Universidad de Santiago de Compostela. Catedrático de Derecho Administrativo, Director del departamento de Derecho Administrativo de la Universidad de La Coruña y Presidente de la Sección Española del Instituto Internacional de Ciencias Administrativas. Consejero de la red Eurolatinoamericana de Derecho Administrativo. Miembro de la Academia Internacional de Derecho Comparado de la Haya, de las real Academia Española de Jurisprudencia, de la Academia Iberoamericana de Derecho Electoral.
}

Jaime Rodríguez-Arana ${ }^{a}$ rajaime@gmail.com Fecha de recepción: 5 de Enero 2014 Fecha de revisión: 1 de Marzo 2014 Fecha de aceptación: 12 de Marzo 2014
MISIÓN JURÍDICA

Revista de Derecho y Ciencias Sociales Bogotá, D.C. (Colombia)

Colaboradores Externos Internacionales Núm. 6, Año 2013

enero-diciembre, pp. 23-56.

ISSN 1794-600X 


\section{PALABRAS CLAVE}

Persona, Derechos fundamentales, Interés general, Derecho administrativo, Constitución.

\begin{abstract}
The fundamental right to good administration, as established in Article 41 of the Charter of Fundamental Rights of the European Union in December 2000, entails a rethinking of administrative law as a whole. Now, with citizens at its heart and with their active participation in shaping the general interest, administrative law and its main categories must be recreated, because the relevance of the fundamental rights of a person now evokes new ways of understanding the system of administrative law.
\end{abstract}

\section{KEYWORDS}

Person, Fundamental rights, General interest. Administrative law, Constitution.

\section{RESUMO}

0 direito fundamental à boa administração, como está estabelecido no artigo 41 da Carta dos Direitos Fundamentais da União Europeia em Dezembro de 2000, traz uma reavaliação do direito administrativo como um todo. Agora, a partir da centralidade do cidadão e de sua participação ativa na definição do interesse geral, o direito administrativo e as suas principais categorias devem ser reformuladas já que agora a relevância dos direitos fundamentais da pessoa sugere novas formas de compreender o sistema de direito administrativo.

\section{PALAVRAS-CHAVE:}

Pessoa, Direitos fundamentais, Interesse geral, Direito administrativo, Constituição.

\section{INTRODUCCIÓN}

De un tiempo a esta parte, el término buena administración ha salpicado la vida de las empresas y de las instituciones públicas de manera creciente en un intento de mejorar el contenido de la propia actividad de conducción o manejo de estas instituciones, de estas corporaciones. A la altura del tiempo en el que estamos, en plena crisis económica y financiera en el mundo occidental, no sabemos todavía si la emergencia de este concepto en los principales documentos de estrategia empresarial o pública está produciendo efectos sustanciales en la manera de dirigir.

En realidad el tema es estructural y se refiere a la recuperación de la perspectiva ética, de servicio objetivo a la ciudadanía, que siempre ha caracterizado a las administraciones públicas. Quizás tengamos que esperar algún tiempo para saber si estamos ante una moda pasajera o si, por el contrario, así lo esperamos, nos hallamos ante un aspecto permanente, material, que afecta el proceso dinámico del arte o de las técnicas de dirección gobierno en la Administración pública

En cualquier caso, lo que sí parece evidente, dada la grave situación de crisis económica, integral, que atravesamos, es que la forma de gobernar, de administrar las instituciones públicas, al menos en el mundo occidental, debe cambiar sustancialmente. La ineficiencia, ineficacia $\mathrm{y}$, sobre todo, el sistemático olvido del servicio objetivo al interés general en que debe consistir la esencia de la administración pública, aconsejan nuevos cambios en la forma de comprender el sentido que tiene el gobierno y administración del interés general.

La buena Administración pública es un derecho de los ciudadanos, nada menos que un derecho fundamental, y, también, un principio de actuación administrativa. Los ciudadanos tienen derecho a exigir determinados patrones o estándares en el funcionamiento de la Administración. Y la Administración está obligada, en toda democracia, a distinguirse en su actuación cotidiana por su servicio objetivo al interés general.

Las páginas que siguen se circunscriben a ambas perspectivas. Al derecho a la buena Administración pública y al principio de buena Administración pública. Estas dos consideraciones están muy vinculadas a la innovación en la Administración porque solo se podrán producir cambios relevantes si el ciudadano cada vez es más consciente de su papel en relación con la Administración y exige de verdad sus derechos y, por otra parte, si los organismos públicos actúan sobre la base de la buena Administración pública. 
El principio, y obligación, de la buena Administración pública, vincula la forma en que se deben dirigir las instituciones públicas en una democracia avanzada. Dirigir en el marco de la buena Administración pública supone asumir con radicalidad que la Administración pública existe y se justifica, en la medida en que sirve objetivamente al interés general.

Las instituciones públicas en la democracia no son de propiedad de sus dirigentes, son del pueblo que es el titular de la soberanía. El responsable tiene que saber, y practicar, que ha de rendir cuentas continuamente a la ciudadanía y que la búsqueda de la calidad en el servicio objetivo al interés general debe presidir toda su actuación.

Hoy es frecuente que las nuevas Constituciones en los diferentes países del globo incorporen como nuevo derecho fundamental el derecho a la buena Administración pública. Por una poderosa razón: porque la razón de ser del Estado y de la Administración es la persona, la protección y promoción de la dignidad humana y de todos sus derechos fundamentales.

En el presente, momento de profunda crisis en tantos sentidos, la indignación reinante también se canaliza hacia la exigencia de una buena Administración pública que trabaje sobre la realidad, desde la racionalidad y, centrada en el ser humano, actúe con mentalidad abierta, buscando el entendimiento y haciendo gala de una profunda sensibilidad social.

En fin, a lo largo de estas páginas, se analizarán las implicaciones de la buena Administración pública en relación con algunos de los aspectos más destacados de la acción pública, tales como la centralidad del ser humano, la apertura a la realidad, la metodología del entendimiento, la participación cívica, la modernización permanente, la vinculación ética o la sensibilidad social.

Igualmente, estudiaremos con la brevedad del caso, las características más sobresalientes del derecho fundamental de la persona a la buena Administración, partiendo esencialmente del Ordenamiento europeo en materia de derechos fundamentales que es, en este momento, la principal Carta de los derechos humanos.
Un conocido autor y destacado asesor de diferentes programas de reformas de gobiernos y administraciones de todo el mundo como Crozier señaló recientemente que, a su juicio, la mayor parte de los procesos de reformas administrativas fallidos lo habían sido por el sistemático olvido de la opinión de los ciudadanos en relación con el enfoque y orientación de las más diversas políticas públicas.

El comentario, desde luego, no tiene desperdicio. Es decir, debe tenerse muy presente en materia de buena Administración pública porque forma parte de su esencia. ¿De qué serviría una Administración pública técnicamente, perfectamente articulada, con procedimientos adecuadamente elaborados y con unos magníficos procesos de políticas públicas, si no estuviera conectada a la realidad, no potenciara la participación cívica, se olvidara de las condiciones sociales o usara a la ciudadanía como justificación para su crecimiento incontrolado?.

La buena Administración pública, más en tiempos de crisis, ha de estar comprometida radicalmente con la mejora de las condiciones de vida de las personas, ha de estar orientada a facilitar la libertad solidaria de los ciudadanos. Para ello es menester que su trabajo se centre sobre los problemas reales de la gente y procure buscar las soluciones escuchando a los sectores implicados.

La buena Administración pública tiene mucho que ver con la adecuada preparación de las personas que dirigen en los organismos públicos. Deben tener mentalidad abierta, metodología del entendimiento y sensibilidad social. Deben trabajar sobre la realidad, utilizar la razón y contemplar los problemas colectivos desde perspectivas de equilibrio para ser capaces de entender dichos problemas y contemplar la pluralidad de enfoques y dimensiones que encierran, situando en el centro al ser humano y sus derechos inviolables.

La dimensión ética incorpora un componente esencial a la buena Administración: el servicio objetivo al interés que ha de caracterizar, siempre y en todo caso, la acción administrativa y la impronta directiva de los responsables.

En este tiempo de crisis, la perspectiva finalista del poder ha hecho acto de presencia con inusitada 
fuerza. El poder, en esta orientación tan presente en nuestros países, ya no es un medio para la mejora de las condiciones de vida de las personas. Es, desde la perspectiva tecnoestructural, ocasión $\mathrm{y}$ forma de enriquecimiento y de influencia creciente de los dirigentes.

Además, desde la dimensión estática del Estado del bienestar, muchas administraciones públicas, especialmente en el denominado mundo occidental, han estado tomadas por personajes dispuestos, como sea, a mantenerse en el poder. Para ello no han dudado en poner en marcha esa fabulosa maquinaria de subvenciones, subsidios y dádivas de toda especie, con el fin de mantener bajo control a la ciudadanía.

\section{PREGUNTA DE INVESTIGACIÓN}

La cuestión objeto de investigación reside en proyectar sobre el actual modelo de Derecho Administrativo de corte unilateral la consideración de la centralidad de la dignidad humana, propiamente a partir de la emergencia del principio general del Derecho Administrativo a la Buena Administración y, sobre todo, desde la perspectiva de la construcción de un nuevo derecho fundamental de la persona a una buena Administración pública.

\section{METODOLOGÍA}

La metodología empleada parte de los postulados del pensamiento abierto, plural, dinámico y complementario aplicados sobre el modelo del Estado social y democrático de Derecho en el que discurre el actual Derecho Administrativo, entendido como el Derecho del servicio objetivo al interés general o el Derecho del Poder público para la libertad solidaria del ciudadano.

\section{RESULTADOS}

Los resultados apuntan a un nuevo enfoque general para entender y comprender mejor el Derecho Administrativo desde la centralidad de la dignidad del ser humano. En especial, el derecho fundamental de la persona a la buena Administración pública trae consigo un conjunto de derechos, componente que va a alterar el sentido de instituciones tan relevantes como el procedimiento administrativo o la jurisdicción contencioso administrativa

\section{EL PRINCIPIO DE LA BUENA ADMINISTRACIÓN}

Una buena Administración pública es aquella que cumple con las funciones que le son propias en democracia. Es decir, una Administración pública que sirve objetivamente a la ciudadanía, que realiza su trabajo con racionalidad, justificando sus actuaciones y que se orienta continuamente al interés general. Un interés general que en el Estado social y democrático de Derecho reside en la mejora permanente e integral de las condiciones de vida de las personas.

Ni que decir tiene que la Administración pública podrá cumplir cabalmente las funciones que le son propias en democracia si las personas que en ella laboran lo hacen desde el compromiso al servicio objetivo al interés general.

Estas notas o características a las que hemos hecho referencia, no son novedosas ni han sido puestas de manifiesto por primera vez en este tiempo. Si ahora subrayamos la importancia de la buena Administración pública es por contraste. Porque en estos años del modelo estático del Estado del bienestar, la Administración ni ha servido al pueblo, ni lo ha hecho objetivamente, ni, evidentemente, ha tendido al interés general.

Sencillamente, la Administración fue tomada, durante el apogeo del Estado del bienestar que denomino estático, por los grupos políticos y a ella han servido casi en exclusiva. En lugar de explicar y justificar sus decisiones, se encerró en una torre de marfil, y decidió cerrarse a la sociedad consciente de que los partidos controlaban el resto de los poderes para acampar, más o menos, en la impunidad.

En este contexto, la Administración pública creció y creció y a su amparo surgieron todo tipo de estructuras públicas, las más de las veces sometidas al derecho privado, para dar cobijo a la legión de personal de procedencia política que había que colocar para retribuir servicios prestados. Las manifestaciones de la mala Administración pública no se hicieron esperar.

La forma ordinaria de financiación de los servicios públicos fue el recurso al endeudamiento. En lugar de atender a las necesidades colectivas de los ciudadanos, se atendió a las necesidades del mantenimiento en el poder. La negligencia, la ausencia de criterios éticos y la conversión del 
aparato administrativo en una colosal maquinaria de laminación del adversario y de control social, reclamaron la vuelta a la buena Administración pública.

Efectivamente, el aparato administrativo se desvía cíclicamente de sus fines y es necesario poner en marcha una nueva reforma. Por eso, desde el principio de la Administración pública, su reforma ha sido, es, y seguirá siendo, una cuestión esencial, un asunto que acompaña inexorablemente su existencia.

La razón principal se puede encontrar en la necesidad de embridar la tendencia endogámica de la propia Administración pública, y sobre todo, de las personas que en ella laboran. En este sentido, la reforma de la Administración pública en la democracia constituye un trabajo permanente porque es permanente su adecuación a las necesidades colectivas de los ciudadanos y muy especialmente a la generación de las mejores condiciones vitales que permitan el ejercicio de la libertad solidaria de las personas.

Desde esta perspectiva, las reformas administrativas deben levantarse en función de las necesidades públicas de las personas y no en función de los intereses burocráticos o tecnocráticos de las Administraciones públicas. ¿Por qué?. Porque, como bien sabemos, corresponde a los poderes públicos promover las condiciones para que la libertad y la igualdad del individuo y de los grupos en que se integra sean reales y efectivas y remover los obstáculos que impiden o dificulten su plenitud y facilitar la participación de todos los ciudadanos en la vida política, económica, cultural y social.

La ingente tarea que supone construir una buena Administración pública es un aspecto de la vida pública que requiere profundizar en una idea sustancia: asegurar las libertades reales de la gente. Desde esta perspectiva, la Administración pública aparece como uno de los elementos clave para asegurar que las aspiraciones colectivas de los ciudadanos puedan hacerse realidad.

Por lo tanto, la Administración pública nunca podrá ser un aparato que se cierre a la creatividad, o la impida con cualquier tipo de trabas, ni tampoco se podrá dejar -especialmente a los más débiles- al arbitrio de intereses egoístas. La buena Administración pública se realiza desde esta consideración abierta, plural, dinámica y complementaria de los intereses generales, del bienestar integral de los ciudadanos.

En efecto, el pensamiento compatible hace posible que al tiempo que se hace una política de impulso de la sociedad civil, no haya compuertas que limiten una acción de la Administración pública que asegure la libertad de disfrutar, por ejemplo, de una justa y digna jubilación de nuestros mayores, que limiten la libertad de disponer de un sistema de salud para todos, que recorten la libertad de que todos tengan acceso a la educación en todos sus niveles, o acceso a un puesto de trabajo, o sencillamente a disfrutar de la paz.

Por eso, la Administración pública debe ser un entorno de entendimiento y un marco de humanización de la realidad que fomente la dignidad de la persona y el ejercicio de todos los derechos fundamentales de la persona, removiendo los obstáculos que impidan su efectivo cumplimiento.

Una Administración pública que se ajuste adecuadamente a las demandas democráticas ha de responder a una rica gama de criterios que podríamos calificar de internos, por cuanto miran a su propia articulación interior, a los procesos de tramitación, a su transparencia, a la claridad y simplificación de sus estructuras, a la objetividad de su actuación, etc. Pero por encima de todos los de esta índole o, más bien, dotándolos de sentido, debe prevalecer la finalidad de servicio al ciudadano a que vengo haciendo alusión.

En este sentido, no podemos dejar de subrayar insistentemente la centralidad de la persona para la buena Administración pública. Efectivamente, el ser humano, con el cúmulo de circunstancias que lo acompañan en su entorno social, es el auténtico sujeto de los derechos y libertades. A ese hombre, a esa mujer, con su determinada edad, su grado de cultura y de formación, mayor o menor, con su procedencia concreta y sus intereses particulares, propios, legítimos, es a quien la Administración pública sirve para que se pueda desarrollar en libertad solidaria.

En este sentido, el personal al servicio de la Administración pública, para poder desempeñar su tarea con talante de servicio y eficacia necesita, además de los medios y condiciones 
de trabajo adecuados, un constante esfuerzo en su competencia profesional para consolidar una Administración pública que no es una entidad abstracta. La integran personas tan reales como los ciudadanos a los que sirve.

La Administración pública, bajo las directrices del Gobierno, precisa de un razonable margen de autonomía para implementar las políticas públicas necesarias para la mejora de las condiciones de vida de los ciudadanos. En cambio, si, por el contrario, el Gobierno sucumbiera a la tentación de apoderarse de la Administración pública, sería imposible metafísicamente la existencia de una buena Administración.

Por otra parte, una Administración pública al margen del principio de juridicidad, que actuara sin normas de cobertura, en función de los caprichos y deseos de sus dirigentes, sería una mala Administración pública. El sometimiento de la Administración a la Ley y al Derecho es una de las mejores garantías para que la ciudadanía sepa que toda la actuación del complejo GobiernoAdministración: actos, silencios, omisiones, vías de hecho o inactividades, todo, puede ser controlada jurídicamente por los Jueces y Tribunales.

\section{PRINCIPALES CARACTERÍSTICAS DE LA BUENA ADMINISTRACIÓN PÚBLICA}

Veamos a continuación, en términos generales, algunas de las principales características que distinguen, en un Estado social y democrático de Derecho, a una buena Administración pública. Centralidad de la persona, apertura a la realidad, metodología de entendimiento, fomento de la participación, modernización tecnológica al servicio del ciudadano, vinculación ética y sensibilidad social.

\subsection{CENTRALIDAD DE LA PERSONA}

La centralidad de la persona es la primera y principal característica de una buena Administración pública. Hasta el punto de que si no existiera no podría hablarse de una Administración democrática porque lo que caracteriza a la Administración del Estado de Derecho, de la democracia, es precisamente el servicio a la ciudadanía, su tendencia a la mejora de las condiciones de vida de las personas.
En una democracia avanzada las personas ya no son sujetos inertes que, sin más, reciben bienes y servicios de los poderes públicos. Ahora, la cláusula del Estado social y democrático de Derecho trae consigo una nueva funcionalidad para los ciudadanos al convertirse en sujetos activos, protagonistas en la determinación del interés general y en la evaluación de las políticas públicas. Hasta el punto de que por el hecho de ser personas disponen de un derecho fundamental a que los asuntos de la comunidad, los asuntos que se refieren al interés general, deben ser gestionados y administrados de la mejor forma técnica posible. Es decir, para la mejora de las condiciones vitales de las personas, para que cada ser humano se pueda desarrollar en libertad solidaria.

\subsection{APERTURA A LA REALIDAD}

La apertura a la realidad, la aproximación abierta a las condiciones objetivas de cada situación, y la apertura a la experiencia son componentes esenciales, actitudes básicas para la buena Administración pública.

La apertura a la realidad implica que la Administración pública ha de atender a las circunstancias sociales, económicas, culturales y políticas que impregnan su actividad. La perspectiva ideológica, esa que parte de prejuicios teóricos diseñados para su proyección mecánica y unilateral sobre la realidad, no tiene sentido. La experiencia de determinados modelos certifica su fracaso.

Administrar desde la realidad implica también acercarse concienzudamente a los diferentes aspectos que ofrece y tenerlos presentes desde esquemas de moderación y equilibrio con el fin de contemplar armónicamente todas y cada una de las dimensiones que componen la rica pluralidad de la realidad.

Desde la realidad es posible la disposición permanente de corregir y rectificar lo que la experiencia nos muestre como desviaciones de los objetivos propuestos o, más en el fondo, de las finalidades que hemos asignado a la acción pública. La buena Administración pública parte de la realidad pues sólo desde ella se puede mejorar el presente para construir un mejor futuro. 


\subsection{METODOLOGÍA DEL ENTENDIMIENTO}

La buena Administración pública aspira a colocar en el centro del sistema a la persona y sus derechos fundamentales. Desde este punto de vista, es más sencillo y fácil llegar a acuerdos unos con otros porque de lo que se trata es de una acción pública de compromiso real con la mejora de las condiciones vitales de los ciudadanos.

En efecto. Cuando las personas son la referencia del sistema político, económico y social, aparece un nuevo marco en el que la mentalidad dialogante, la atención al contexto, el pensamiento reflexivo, la búsqueda continua de puntos de confluencia, la capacidad de conciliar y de sintetizar, sustituyen a las bipolarizaciones dogmáticas y simplificadoras, y dan cuerpo a un estilo que, como se aprecia fácilmente, busca, por encima de todo, mejorar las condiciones de vida de la gente.

El método del entendimiento supone que la confrontación no es lo sustantivo del procedimiento democrático. Ese lugar le corresponde al diálogo. La confrontación es un momento del diálogo, como el consenso, la transacción, el acuerdo, la negociación, el pacto o la refutación. Todos son pasajes, circunstancias, de un fluido que tiene como meta de su discurso el bien social, que es el bien de la gente, de las personas, de los individuos de carne y hueso. Si la administración del sector público, la buena Administración, discurre por estos derroteros las posibilidades de entendimiento de unos con otros son grandes.

La buena Administración pública se hace entender, necesita afirmar, explicar, aclarar, razonar. Por una razón elemental: porque el dueño y señor de la Administración pública es el pueblo, y a él los dirigentes deben rendir cuentas permanentemente de las decisiones que adoptan.

En el Estado de Derecho es fundamental que los administradores de la cosa pública se habitúen a la rendición de cuentas sobre sus decisiones $y$, sobre todo, a que el poder se ejerza desde la explicación, desde la razón, desde la luz, desde la transparencia, desde la motivación inherente a la posición que se tiene desde arriba.

\subsection{PROMOCIÓN DE LA PARTICIPACIÓN}

La buena Administración pública significa, entre otras consideraciones, poner como centro del trabajo público la preocupación de los ciudadanos, de la gente: sus aspiraciones, sus expectativas, sus problemas, sus dificultades, sus ilusiones. Pero no de cualquier manera, contando con las personas, con las destinatarias del quehacer público que realizan las Administraciones públicas.

En efecto, la buena Administración supone la necesidad de contar con la presencia y participación real de la ciudadanía, de toda la ciudadanía, evitando que las fórmulas cerradas que proceden de las ideologías de este nombre expulsen de su consideración a determinados sectores sociales.

En este sentido, la buena Administración no puede atender tan sólo los intereses de un sector, de un grupo, de un segmento social, económico o institucional, ya que una condición de estos nuevos espacios es el equilibrio, entendiendo por tal, la moderación y atención a los intereses de todos. Preocuparse sólo por el interés de algunos, aunque se trate de grupos mayoritarios, significa prescindir de otros, y consecuentemente practicar un exclusivismo que es ajeno a la buena Administración pública.

Por eso, la determinación de los objetivos de las políticas públicas no puede hacerse realmente si no es desde la participación ciudadana. La participación ciudadana se configura como un objetivo público de primer orden ya que constituye la esencia de la democracia y, por ello, ocupa un lugar sobresaliente entre los parámetros centrales de la buena Administración pública.

Una actuación pública que no persiga, que no procure un grado más alto de participación ciudadana, no contribuye al enriquecimiento de la vida democrática y se hace, por lo tanto, en detrimento de los mismos ciudadanos a los que se pretende servir. Pero la participación no se formula solamente como objetivo político, sino que las nuevas políticas públicas reclaman la práctica de la participación como método.

Tratar de la participación como método es tratar de la apertura del gobierno y la administración pública que la quiere practicar hacia la sociedad. Una organización cerrada no puede pretender captar, representar o servir los intereses propios de la ciudadanía. 
La condición de esa apertura es una actitud, una disposición, alejada de la suficiencia y de la prepotencia, propia tanto de las formulaciones ideológicas como de las tecnocráticas. Pero las actitudes $\mathrm{y}$ las disposiciones necesitan instrumentarse, traducirse en procesos y en instrumentos que las hagan reales. Y la primera instrumentación que exige una disposición abierta es la comunicativa, la comunicación.

La buena Administración pública exige receptividad: tener la sensibilidad suficiente para captar las preocupaciones e intereses de la sociedad en sus diversos sectores y grupos, en los individuos y colectividades que la integran. No se trata simplemente de apreciaciones globales, de percepciones intuitivas, ni siquiera simplemente de estudios o conclusiones sociométricos. Se precisa diálogo real. Y diálogo real significa interlocutores reales, concretos, que son los que encarnan las preocupaciones y las ilusiones concretas, las reales, las que pretendemos servir.

A mi juicio, una de las finalidades -si no la principal- que mejor define la buena Administración pública es la de la participación, la libre participación de la gente en los asuntos públicos.

En efecto, la referencia a la libertad, además de centrarnos de nuevo en la condición personal de la persona, nos remite a una condición irrenunciable de su participación, su carácter libre, pues sin libertad no hay participación. La participación no es un suceso, ni un proceso mecánico, ni una fórmula para la organización de la vida social. La participación, aunque sea también todo eso, es más: significa la integración del individuo en la vida social, la dimensión activa de su presencia en la sociedad, la posibilidad de desarrollo de las dimensiones sociales del individuo, el protagonismo singularizado de todos los hombres y mujeres.

En este sentido la participación no puede regularse con decretos ni con reglamentos. Sólo hay real participación -insisto- si hay participación libre. De la misma manera que la solidaridad no puede ser obligada. Esta relación de semejanza entre participación y solidaridad no es casual, por cuanto un modo efectivo de solidaridad, tal vez uno de los más efectivos, aunque no sea el más espectacular, sea la participación, entendida como la preocupación eficaz por los asuntos públicos, en cuanto son de todos y van más allá de nuestros exclusivos intereses individuales.

Ahora bien, al calificar la participación como libre, quiero referirme no sólo a que es optativa sino también a que, en los infinitos aspectos y modos en que la participación es posible, es cada vecino quien libremente regula la intensidad, la duración, el campo y la extensión de su participación.

La diversificación de intereses, impulsados por un clima de participación y compromiso cada vez mayores con los asuntos públicos, sobre todo -aunque no exclusivamente-, por parte de los jóvenes, ha culminado en el establecimiento de un denso tejido asociativo, con intereses, sensibilidades e incluso planteamientos políticos diversos.

En ese tejido deben buscarse -sin exclusiones preestablecidas- a los interlocutores: asociaciones y colegios profesionales, asociaciones de padres de alumnos, asociaciones de amas de casa, de mujeres, grupos juveniles; entidades deportivas y culturales, organizaciones no gubernamentales, grupos, entidades y asociaciones de la tercera edad, asociaciones parroquiales, grupos y asociaciones ecologistas, sectores industriales y empresariales, consumidores, asociaciones y movimientos vecinales, entidades educativas, órganos de la Administración particularmente dirigidos a la atención al público; comisiones de fiestas, medios de comunicación, sociedades gastronómicas, instituciones de recreo y tiempo libre, sociedades de caza y pesca; etc., etc., etc.

La capacidad para establecer un diálogo con el más amplio número de representantes sociales será un indicativo de su apertura real a la sociedad. En ese diálogo no debe olvidarse el objetivo principal que se persigue. No se trata de convencer, ni de transmitir, ni de comunicar algo, sino ante todo y sobre todo, en primer lugar, de escuchar.

Escuchar es, en efecto, una característica de la buena Administración pública. En diálogo escuchar no comporta una disposición pasiva, sino al contrario, es una disposición activa, indagatoria, que busca el alcance de las palabras del interlocutor, comprender su manera de percibir la realidad, la conformación de sus 
preocupaciones y la proyección de sus ilusiones y objetivos.

El punto de partida es la correcta disposición de apertura. Sin ella el diálogo será aparente, sólo oiremos lo que queremos oír e interpretaremos de modo sesgado lo que se nos dice. La pretensión de centrarse en los intereses de la gente será ilusoria.

Ese diálogo debe caracterizarse además por su flexibilidad. Es decir, no se trata de un intercambio rígido y formalista; no es una encuesta, está abierto, y han de ponerse en juego los factores personales y ambientales necesarios para hacerlo más confiado y fructífero. En ese mismo sentido ha de tenerse en cuenta el talante personal del interlocutor y contar también con el propio, para que la condición de los interlocutores no sea un elemento de distorsión en la comunicación.

El diálogo debe conducirse sin limitación en los temas salvo que atente a la dignidad de la persona. También interesa conocer, cuando sea el caso el descontento que producimos, a quien y por qué. Y en medio de la multitud de propuestas de solución que se darán, habrá que resaltar que interesa considerarlas todas, pero de modo muy especial las que tengan como rasgo el equilibrio propio del centro, es decir, las que toman en consideración a todos los sectores afectados por el problema que se trate o la meta que se persiga, y no sólo al propio.

\subsection{VINCULACIÓN ÉTICA}

En las formulaciones recientes sobre la buena Administración pública suele estar siempre presente la dimensión ética, seguramente porque se ha caído en la cuenta de que la buena Administración pública debe estar orientada al bienestar integral de los ciudadanos y debe facilitar, por tanto, a quienes son sus destinatarios su mejoramiento personal.

La importancia de la Ética en relación con la muy noble actividad pública continua siendo en el presente uno de los aspectos más complejos de afrontar probablemente porque todavía el poder y el dinero son grandes ídolos a los que se adora con intensa devoción. El poder por el poder, sea financiero o político, explica sobradamente el sentido de la crisis en la que nos encontramos.
En efecto, la relación entre Ética y Administración pública en sentido amplio constituye un problema intelectual de primer orden, de gran calado. Desde los inicios mismos del pensamiento filosófico y a lo largo de toda la historia en Occidente ha sido abordado por tratadistas de gran talla, desde las perspectivas más diversas y con conclusiones bien dispares. Y por mucho que se haya pretendido traducir algunas de ellas en formulaciones políticas concretas, la experiencia histórica ha demostrado sobradamente que ninguna puede tomarse como una solución definitiva de tan difícil cuestión.

El centro de la Administración pública, repito, es la persona, el ciudadano. La persona, el ser humano, no puede ser entendido como un sujeto pasivo, inerme, puro receptor, destinatario inerte de las decisiones públicas

Definir a la persona como centro de la acción pública significa no sólo, ni principalmente, calificarla como centro de atención, sino, sobre todo, considerarla el protagonista por excelencia de la Administración pública. Aquí se encuentra una de las expresiones más acabadas de lo que entiendo por buena Administración pública en el marco democrático.

Afirmar que la libertad de los ciudadanos es el objetivo primero de la acción pública significa, pues, en primer lugar, perfeccionar, mejorar, los mecanismos constitucionales, políticos y jurídicos que definen el Estado de derecho como marco de libertades. Significa también crear las condiciones para que cada hombre y cada mujer encuentre a su alrededor el campo efectivo, la cancha, en la que jugar, libremente su papel activo, en el que desarrollar su opción personal, en la que realizar creativamente su aportación al desarrollo de la sociedad en la que está integrado.

Establecidas esas condiciones, el ejercicio real de la libertad depende inmediata y únicamente de los propios ciudadanos, de cada ciudadano. La buena Administración pública ha de mirar precisamente a la generación de este ambiente en el que cada ciudadano pueda ejercer su libertad de forma solidaria. Para ello, los administradores de la cosa pública han de tener siempre bien presente que la acción pública ha de atender de manera preferente al bienestar integral de todos los ciudadanos. 
El solar sobre el que es posible construir una buena Administración pública es, insistimos una vez más, el de la realidad del ser humano, una realidad no acabada, ni plenamente conocida, por cuanto es personalmente biográfica, y socialmente histórica, pero incoada y atisbada como una realidad entretejida de libertad y solidaridad, y destinada por tanto, desde esa plataforma sustantiva, a protagonizar su existencia.

La buena Administración pública no puede reducirse, pues, a la simple articulación de procedimientos, con ser éste uno de sus aspectos más fundamentales. La buena Administración pública debe partir de la afirmación radical de la preeminencia de la persona, y de sus derechos, a la que los poderes públicos, despejada toda tentación de despotismo o de autoritarismo, deben subordinarse.

La afirmación de la prioridad del ser humano, de la sustancialidad de la persona es el elemento clave de la configuración ética de la buena Administración pública. Pero hablar de configuración ética no puede entenderse como la articulación de una propuesta ética concreta, definida, que venga a constituir una especie de credo o de código de principios dogmáticos desde los que se pretenda hacer una construcción política.

La buena Administración pública, por lo tanto, no puede fundarse, como algunos pretenden que se haga, en la propuesta de soluciones definitivas, perfectamente perfiladas en los gabinetes de los ideólogos que pretenden tener la clave para la interpretación de todo acontecimiento humano. La acción pública se ve orientada por grandes principios generales que en absoluto resuelven, que no dan la fórmula para la solución de problema concreto alguno.

Los grandes principios generales orientan en la búsqueda de soluciones, pueden ser elementos de contraste para un juicio sobre la validez de las soluciones propuestas, pero por sí mismos no resuelven nada, porque las soluciones a los problemas concretos van a depender del juicio prudencial de quienes han de decidir.

En efecto. La validez de la solución aportada vendrá contrastada por la experiencia. No basta comprobar que las soluciones aplicadas están en consonancia teórica con los grandes principios que defendemos. Es necesaria la prueba última de la contrastación empírica, la comprobación de que lo resuelto, lo ejecutado, produce los efectos deseados, o al menos efectos aceptables en la mejora de la situación que se deseaba resolver.

La buena Administración pública opera en un marco de moderación y de conocimiento de la realidad, tratando de mejorarla, lo que es compatible evidentemente con la rectificación sobre la marcha de los errores que se puedan cometer. Pretender que la Administración pública esté libre de tachas o errores es algo metafísicamente imposible que cuándo se cree firmemente se producen grandes desastres.

Podríamos decir que la apertura a la realidad, la aproximación abierta y franca a las condiciones objetivas de cada situación, y la apertura a la experiencia son componentes esenciales, actitudes básicas del talante ético desde el que debe construirse la buena Administración pública. En ellas se funda la disposición permanente de corregir y rectificar lo que la experiencia nos muestre como desviaciones de los objetivos propuestos o, más en el fondo, de las finalidades que hemos asignado a la acción pública.

Pensar la complejidad de la realidad y acercarse a ella desde el supuesto de la propia limitación, al tiempo que acaba con todo dogmatismo, rompe también cualquier tipo de prepotencia en el análisis o en el dictamen de soluciones, a la que el político pueda verse tentado.

El buen administrador público ha de tener claro que no es infalible, que sus opiniones, sus valoraciones están siempre mediatizadas por la información de que parte, que es siempre limitada, necesariamente incompleta.

La Administración pública radicalizada sólo se puede ejercer desde convicciones que se alejan del ejercicio crítico de la racionalidad, es decir, desde el dogmatismo que fácilmente deviene en fanatismo, del tipo que sea.

Sin embargo, toda acción pública es relativa. El único absoluto asumible es el hombre, cada hombre, cada mujer concretos, y su dignidad. Ahora bien, en qué cosas concretas se traduzcan aquí y ahora tal condición, las exigencias que se deriven de ellas, las concreciones que deban establecerse, dependen en gran medida de ese 
"aquí y ahora", que es por su naturaleza misma, variable.

La moderación, lejos de toda exaltación y prepotencia, implica una actitud de prudente distanciamiento, la asunción de la complejidad de lo real y de nuestra limitación. La complejidad de lo real no es una derivación del progreso humano, de los avances científicos y de la tecnología, por mucha complejidad que hayan añadido a nuestra existencia.

Con la actitud de equilibrio quiero referirme a la atención que el administrador público debe dirigir no a un sector, a un segmento de la población, a un grupo, por muy mayoritario que fuese, de ciudadanos, sino que el político debe tener presente la realidad social en todas sus dimensiones.

Se trata de administrar para todos, contando con los intereses y las necesidades de todos, y también y sobre todo con las de los que no las expresan, por cuanto entre ellos se encuentran posiblemente los que tienen más escasez de medios o menos sensibilidad para sentir como propios los asuntos que son de todos. Equilibrio, pues, como garantía, también, del buen gobierno y la buena administración.

El equilibrio es una exigencia y una condición de la buena Administración pública. El administrador público no está comprometido con un segmento, ni con una mayoría por amplia que fuese, sino que lo está con todos, aunque la base social que constituye su soporte serán necesariamente los sectores más dinámicos, activos y creativos del cuerpo social.

Al tratar acerca de las condiciones objetivas de las diversas situaciones a las que el administrador público se enfrenta, podría interpretarse que deben atender sólo a lo que podríamos llamar condiciones reales, prescindiendo de las referencias a la subjetividad, a las inclinaciones, a la conciencia de las gentes, al sentir social.

Nada más lejos de lo que debe ser. El sentir social, la conciencia social, debe ser un elemento de primer orden en la consideración del administrador público, si realmente se admite que la ciudadanía es el elemento fundamental en la articulación de la vida política. El sentir social forma parte de las condiciones objetivas, porque es un factor que actúa realmente, que gravita sobre las situaciones reales, y debe ser tenido en cuenta en su valoración.

Por ello, una buena Administración pública debe tener muy en cuenta la opinión pública. Sería suicida, pero sobre todo sería inadecuado e injusto, actuar de espaldas a ella. Pero la acción pública no puede plantearse como un seguidismo esclavizado de esa opinión. Negar una crisis que está instalada ya en la sociedad es, en este sentido, un grave error que tarde o temprano el pueblo cobra.

La atención a la opinión pública no significa sólo atención a la opinión mayoritaria, ni mucho menos. El buen administrador público debe tener particular sensibilidad para atender a las demandas de grupos y sectores minoritarios que manifiestan un especial compromiso éticopolítico en la solución de graves problemas que aquejan a nuestra sociedad y, trascendiéndola, al mundo entero, y que representan, en cierto modo, aquello que se denominaba conciencia crítica de la sociedad.

La conciencia ecológica, el antimilitarismo, el reparto de la riqueza, el compromiso con los desposeídos, la crítica de una sociedad consumista y competitiva, la reivindicación de la dignidad de la condición femenina, la denuncia de una sociedad hedonista y permisiva, etc., son tantas manifestaciones de una particular sensibilidad ética.

A veces, es cierto, estas tomas de postura se hacen con manifestaciones desmesuradas y reduccionistas o totalizantes, pero que nunca el administrador público debe dejar de tener presentes, con el equilibrio y mesura que deben caracterizarle. Una respuesta cumplida a las demandas y expectativas de la sociedad de nuestro tiempo, requiere estar abierto también a las nuevas sensibilidades y hacer una ponderada valoración de sus diversas manifestaciones, sabiendo distinguir los compromisos auténticos de los oportunismos y de las estrategias de lucha partidista.

Las sociedades democráticas son fundamentalmente, esencialmente, sociedades plurales, hasta el punto de que un pluralismo disminuido o menoscabado puede ser interpretado como un síntoma de déficit democrático. La buena 
Administración pública ha de comprometerse con el pluralismo real, no con ese falso pluralismo de salón que no es más que una burda manipulación.

El pluralismo auténtico se traduce en diálogo. Cuando existe diversidad social, pero no hay diálogo, propiamente no deberíamos hablar de pluralismo sino de sectarismo. Aquí nos encontraríamos otra vez con la división maniquea del cuerpo social característica de todo comportamiento sectario.

Hoy, a pesar de la insistencia en la buena Administración pública, la proliferación de talantes autoritarios en la escena democrática constituye una no pequeña preocupación en la medida en que pareciera que la democracia es susceptible de un uso alternativo por estos nuevos autoritarismos que acechan por doquier.

Posiblemente en el diálogo es donde más pueden apreciarse las condiciones que caracterizan el talante de la buena Administración pública: moderación, respeto mutuo, conciencia de la propia limitación, atención a la realidad y a las opiniones ajenas, actitud de escucha, etc.

La disposición al diálogo no debe ser sólo una actitud de la buena Administración pública. El diálogo, como actitud socialmente generalizada, debe ser un objetivo público de primer orden.

Una sociedad democrática no es tanto una sociedad que vota, ni una sociedad partidista, con ser estos elementos factores vertebradores fundamentales en una democracia. Una sociedad democrática es ante todo una sociedad en la que se habla abiertamente, en la que se hace un ejercicio público de la racionalidad, en la que las visiones del mundo y los intereses individuales y de grupo se enriquecen mutuamente mediante el intercambio dialógico.

El diálogo auténtico entraña un enriquecimiento de la vida social y una auténtica integración, pues el diálogo supone la transformación de la tolerancia negativa, el mero soportar o aguantar al otro, al distinto, en tolerancia positiva, que significa apreciar al otro en cuanto que no nos limitamos simplemente a existir a su lado, sino que coexistimos con él.

\subsection{INNOVACIÓN Y SOCIEDAD DEL CONOCIMIENTO}

En el ámbito de las nuevas tecnologías, en el ámbito de la sociedad de la información y del conocimiento, tenemos que ser conscientes de que hay que combinar y que hay que trabajar en alianza estratégica con los derechos fundamentales de las personas.

La buena Administración pública no puede olvidar que la sociedad del conocimiento ha de mejorar la calidad de la cultura cívica de las personas, pues de lo contrario estaremos desaprovechando una magnífica oportunidad para incidir positivamente en la mejora de las condiciones de vida de los ciudadanos.

En la nueva sociedad del conocimiento, se ha hablado mucho, se ha escrito mucho, sobre cómo tienen que concebirse las organizaciones. Por ejemplo, se ha señalado que deben ser de organizaciones inteligentes, flexibles, organizaciones humanas, abiertas, no rígidas, no herméticas, no verticales, no artificiales y no piramidales.

Me parece de gran interés la afirmación de Alejandro Llano, quien dice que la clave en estas organizaciones de la sociedad del conocimiento tiene mucho que ver con el proceso artesanal del aprendizaje. La formación no termina nunca, como sabemos muy bien, y el conocimiento es crecimiento, también como persona.

Los saberes que se producen a través de las nuevas tecnologías deben ayudar también a mejorar el trabajo diario de la organización y a mejorar también el trabajo de las personas que forman parte de la Administración pública, sin olvidar que hay una dimensión ética inherente a la propia Administración, tal y como analizamos en el epígrafe precedente.

En este marco, la buena Administración pública asume un papel básico y fundamental en la medida en que, en una sociedad democrática, la administración de lo público debe realizarse desde la condición central del ser humano y desde la convicción de que el poder público es una institución para mejorar las condiciones de vida de los ciudadanos.

Por supuesto que en la sociedad del conocimiento lo importante son las personas. 
Las personas no son mercancías; las personas tienen un potencial de libertad e inteligencia muy importante y los buenos administradores públicos tienen que ser capaces de hacer aflorar esas potencias, esa capacidad de aportación de ideas, esa capacidad de intercambio de ideas, esa capacidad de generar confianza para transformar la realidad.

En la sociedad del conocimiento, donde Internet, la red, tiene tanta importancia, tenemos que ser conscientes de que la clave está en concebir los conocimientos como capacidad para mejorar la vida de los hombres, no en acumular todo un conjunto de información que viene por la red y que no se sabe para qué sirve.

Sin embargo, comprobamos que para mucha gente ocurre eso que anunciaba Jeremy Rifkin, 24 horas, 7 días a la semana. Estamos intentando que los trabajadores vivan en mejores condiciones, en unas nuevas condiciones más humanas de trabajo, y estamos obligando, muchas veces, a que los empleados estén conectados al ordenador 24 horas los 7 días de la semana, sábados y domingos incluidos. 0 que a través de los móviles, resulta que se puede tener a los trabajadores en un permanente sentido de dependencia que dañe incluso la vida de familia.

La sociedad del conocimiento nos facilita saber más para pensar mejor. Las organizaciones son, como señala Llano, comunidades de aprendizaje, de investigación. En efecto, si en una organización hay un deseo de mejora, si continuamente se analizan los resultados: ¿por qué las cosas salen bien?, ¿por qué salen mal?, y ¿qué cambios se deben procurar desde el trabajo en equipo, desde la escucha de los colaboradores?, entonces es más fácil saber lo que se debe hacer en cada momento.

Las transformaciones tecnológicas están determinando un nuevo tipo de sociedad, que abandona a marchas forzadas su carácter postindustrial para configurarse, como se ha dicho, como una sociedad del conocimiento y de la información. Ahora bien, esta sociedad del conocimiento y de la información tiene que ser también una sociedad humana, profundamente humana, en la cual resplandezcan los derechos fundamentales y la dignidad de las personas.

Pensamos en una sociedad donde resplandezcan los derechos fundamentales de los que menos condiciones tienen de salir adelante. Y esta nueva sociedad que está emergiendo poco a poco, ofrece muchas potencialidades para mejorar la vida de los ciudadanos desde las vertientes pública y privada. Se habla de la nueva economía, de los nuevos canales comerciales, de la nueva democracia, más directa y más participativa, se habla también de nuevas formas de concebir y ejecutar las políticas públicas.

Desde la buena Administración pública hay que pensar que los poderes públicos tienen el gran desafío de mejorar las condiciones para el libre desarrollo solidario de los ciudadanos.

La importancia que las nuevas tecnologías de la información y la comunicación tienen en la mejora de las relaciones entre Administración pública y ciudadanos es evidente.

Solo hay que pensar en las posibilidades que las TIC ofrecen al ciudadano para acceder a la información pública, en las posibilidades que tiene la organización de informar con más transparencia a la población, en la posibilidad de hacer participar al ciudadano en la toma de decisiones o en la definición de sus necesidades colectivas. La simplificación que puede representar para la organización pública la puesta en común de recursos, evitando trámites e informaciones innecesarias y duplicaciones de tareas se impone por sí misma.

Las ventajas de las nuevas tecnologías son evidentes, sobre todo en orden a recuperar, en la práctica, esa idea central del pensamiento democrático de que las instituciones son de la propiedad ciudadana.

Las distintas Administraciones públicas, a lo largo $\mathrm{y}$ ancho del planeta, han avanzado sustancialmente en esta materia. Ahí están las ventanillas únicas que permiten la interconexión de registros, la ventanilla única empresarial que agiliza la creación de empresas, el portal de las Administraciones públicas, la Intranet administrativa, la regulación de la ley de firma electrónica, el documento nacional de identidad electrónico, la gestión telemática de determinados trámites administrativos, como las cotizaciones a la Seguridad Social o la declaración y pago de impuestos... 
Sin embargo, hay que reconocer que aún queda camino que recorrer en la implantación de una autentica Administración electrónica que garantice mayores cotas de eficacia, de eficiencia y de calidad de los servicios, así como más cercanía a los ciudadanos.

Para que la Administración pública on-line tenga sentido, el desarrollo en el interior de la organización pública debe ir en paralelo al propio desarrollo tecnológico de la sociedad. Por ello, no solo hay que hacer esfuerzos por implantar la e-Administración, sino que también hay que priorizar la extensión del uso de las nuevas tecnologías en la sociedad, minimizando la brecha social que se puede producir según se use o no la información.

Hemos de admitir que en muchos países del globo el acceso a Internet es escaso entre la población a pesar de los esfuerzos económicos que se están realizando por implantar el uso del ordenador a las escuelas, o por hacer más económico el acceso a Internet. Esta realidad, y la adopción de determinadas medidas, como mejorar la seguridad electrónica, garantizar la confidencialidad, son claves para que cobre sentido la Administración en línea.

Una nueva cultura, tecnológica y profundamente humanista a la vez, es la que impregna la buena Administración pública. Este ambiente debe presidir la propia organización, los métodos de trabajo, las gestiones administrativas, los procedimientos, la prestación de servicios públicos. Para que esta nueva cultura tecnológica y humana, radicalmente tecnológica y radicalmente humana, penetre verdaderamente, es muy importante trabajar en el mundo de la educación y de la formación.

Por eso, en una institución como el Instituto Nacional de Administración Pública es esencial insistir y subrayar la formación de los funcionarios en el manejo de los nuevos instrumentos informáticos de gestión, sin perder de vista algo fundamental: que las TIC no son un fin en sí mismas, son un medio para conseguir una Administración pública más humana que facilite el libre ejercicio de los derechos fundamentales de las personas.

La buena Administración pública en la sociedad del conocimiento trae consigo seis formas de entender el trabajo que se realiza en las dependencias públicas que, de la mano de Alejandro Llano, me parecen muy relevantes para comprender el sentido de la tarea administrativa.

Primera, trabajar es aprender. Dirigir es enseñar. Trabajar es aprender porque el aprendizaje es permanente y no se puede deslindar el trabajo del aprendizaje. En el puesto de trabajo aprendemos en convivencia con los demás colaboradores, colegas, por lo que el que dirige no se puede guardar para sí lo que ha aprendido de otros, sino que generosamente tiene que transmitirlo a los demás en un camino en el que se hace escuela y se descubren buenos directivos para lo público y para lo privado.

En segundo lugar, una organización inteligente es una comunidad de investigación y aprendizaje. Permanentemente hemos de buscar las causas de lo que sale bien, de lo que sale mal y tomar decisiones. Y a la hora de los diagnósticos, de los análisis, tenemos que contar con toda la organización, con todas las personas que trabajan, que están involucradas en los objetivos y en los resultados.

En tercer lugar, entender el conocimiento nos lleva a una nueva forma de entender la profesión que tiene mucho que ver con la orfebrería, tarea que está vinculada a la elaboración esmerada del trabajo, a la minuciosidad y laboriosidad propia del trabajo de los artesanos dedicados al montaje $\mathrm{y}$ tratamientos de las joyas y las piedras preciosas. Lo importante es el trabajo, lo bien que se haga el trabajo, produzca o no el resultado buscado. Si el fin opaca al medio, mal asunto, mal asunto.

En cuarto lugar, estas organizaciones propias de la buena Administración pública poseen una obvia dimensión ética. La persona en el centro, en el centro de trabajo, tiene que ser la característica que distinga el trabajo de las nuevas organizaciones de la sociedad del conocimiento. Si la persona es una mercancía de usar y tirar, mal, muy mal.

En quinto lugar, una organización inteligente también debe cultivar una profunda cultura corporativa, y si es una organización pública su talante y su estilo estarán al servicio objetivo y permanente de los intereses generales. Intereses generales entendidos como la garantía de los derechos de las personas. 
$\mathrm{Y}$ en sexto lugar, en las organizaciones inteligentes, la investigación y la gestión se identifican. ¿Por qué? Porque el aprendizaje no termina nunca, la formación no termina nunca y gestionar es aprender, y gestionar, como decía antes, es investigar. La buena Administración pública, en fin, no puede olvidar estos criterios tan importantes para realizar, en la sociedad del conocimiento, de la mejor forma posible, el servicio objetivo al interés general.

\subsection{SENSIBILIDAD SOCIAL}

Una de las características que mejor define a la buena Administración pública es la sensibilidad social. En efecto, la sensibilidad social, actitud solidaria, deriva del principio de la centralidad de la persona en la actuación de la Administración pública. Perspectiva que permite conducir la proa de la nave del aparato administrativo a la búsqueda las soluciones reales a las cuestiones colectivas y a orientar las decisiones en los ámbitos de la cooperación, de la convivencia, de la integración y de la confluencia de intereses. En este contexto, la persona y su dignidad son la clave y la fuerza que llevan a la gran tarea de humanizar desde la misma Administración.

La sensibilidad social supone, insisto, colocar a las personas en el centro de la actuación administrativa. Cuándo ello así acontece, la acción pública se dirige de manera comprometida a prestar servicios reales al pueblo, a atender los intereses reales de la gente, a escuchar de verdad a la ciudadanía. Ello implica necesariamente el entendimiento con los diferentes interlocutores para mejorar las condiciones de vida de los ciudadanos.

Ahora bien, esas prestaciones, esos servicios no son un fin sino un medio para alcanzar mayores cotas de bienestar general e integral para el pueblo. Son un medio para la mejora de las condiciones de ejercicio de la libertad solidaria de las personas, no un sistema de captación de voluntades.

En fin, las prestaciones sociales, las atenciones sanitarias, las políticas educativas, las actuaciones de promoción del empleo, son bienes de carácter básico que una buena Administración pública debe poner entre sus prioridades, de manera que la garantía de esos bienes se convierta en condición para que la sociedad libere energías que permitan su desarrollo y la conquista de nuevos espacios de libertad y de participación ciudadana.

Las prestaciones públicas constituyen el entramado básico del llamado Estado del bienestar, modelo que poco a poco va camino de su desaparición salvo que proyectemos el quehacer público desde la perspectiva dinámica del Estado del bienestar.

Por eso, ¿cómo es posible seguir defendiendo la subvención como fin, cuando es uno de los mayores atentados al progreso social?. En efecto, cuando el Estado de bienestar se toma como un fin en sí mismo, la Administración pública se reduce al papel de suministrador de servicios, con lo que el ámbito público se convierte en una rémora del desarrollo social, político, económico y cultural, en lugar de su catalizador o impulsor.

En este ambiente se dificulta, cuando no se impide desde la raíz, el necesario equilibrio para la creación de una atmósfera adecuada para el libre desarrollo de las personas y de las asociaciones, levantándose una estructura estática y cerrada que priva al cuerpo social del dinamismo necesario para propiciar la libertad y la participación de la ciudadanía.

Las prestaciones, los derechos, tienen un carácter dinámico que no puede quedar a merced de mayorías clientelares, anquilosadas, sin proyecto vital más allá de la reivindicación del derecho adquirido o de la conservación de la posición. Cuando ello acontece, se olvida que las prestaciones sociales se justifican en la medida en que se incardinan en el bienestar general e integral de la gente, o, si se quiere, en la mejora de las condiciones de vida de los ciudadanos.

Nos puede servir como ejemplo la acción de la Administración pública en relación con los más desfavorecidos, entre los que contamos a los marginados, los pobres, los parados o los mayores. Las prestaciones públicas nunca pueden tener la condición de dádivas mecánicas. Más bien, la buena Administración pública debe propiciar con sus prestaciones el desarrollo, la manifestación, el afloramiento de las energías y las capacidades escondidas en esos amplios sectores sociales. 


\section{EL DERECHO FUNDAMENTAL A LA BUENA ADMINISTRACIÓN PÚBLICA}

El Derecho Administrativo del Estado social y democrático de Derecho es un Derecho del poder público para la libertad solidaria, un Ordenamiento jurídico en el que las categorías e instituciones públicas han de estar, como bien sabemos, orientadas al servicio objetivo del interés general. Atrás quedaron, afortunadamente, consideraciones y exposiciones basadas en la idea de la autoridad o el poder como esquemas unilaterales desde los que plantear el sentido y la funcionalidad del Derecho Administrativo.

En este tiempo en que nos ha tocado vivir, toda la construcción ideológica montada a partir del privilegio o de la prerrogativa va siendo superada por una concepción más abierta y dinámica, más humana también, desde la que el Derecho Administrativo adquiere un compromiso especial con la mejora de las condiciones de vida de la población a partir de las distintas técnicas e instituciones que componen esta rama del Derecho Público.

El lugar que antaño ocupó el concepto de la potestad o del privilegio o la prerrogativa ahora lo ocupa por derecho propio la persona, el ser humano, que asume un papel central en todas las ciencias sociales; también, obviamente, en el derecho administrativo.

En efecto, la consideración central del ciudadano en las modernas construcciones del Derecho Administrativo y la Administración pública proporciona el argumento medular para comprender en su cabal sentido este nuevo derecho fundamental a la buena Administración pública establecido en el artículo 41 de la Carta Europea de los Derechos Fundamentales.

La persona, el ciudadano, el administrado o particular según la terminología jurídico administrativa al uso, ha dejado de ser un sujeto inerte, inerme e indefenso frente a un poder que intenta controlarlo, que le prescribía lo que era bueno o malo para él, al que estaba sometido y que infundía, gracias a sus fenomenales privilegios y prerrogativas, una suerte de amedrentamiento y temor que terminó por ponerlo de rodillas ante la todopoderosa maquinaria de dominación en que se constituyó tantas veces el Estado.
La perspectiva abierta y dinámica del poder, ordenado a la realización de la justicia, a dar a cada uno lo suyo, lo que se merece, ayuda sobremanera a entender que el principal atributo de la Administración pública sea, en efecto, un elemento esencial en orden a que la dirección de la cosa pública atienda preferentemente a la mejora permanente e integral de las condiciones de vida del pueblo en su conjunto, entendido como la generalidad de los ciudadanos.

Tratar sobre buena Administración pública constituye una tarea que ha de estar presidida por los valores cívicos y correspondientes cualidades democráticas, que son exigibles a quien ejerce el poder en la administración pública a partir de la noción constitucional de servicio objetivo al interés general. Poder que debe ser moderado, equilibrado, realista, eficaz, eficiente, socialmente sensible, cooperativo y atento a la opinión pública.

Existen Administraciones públicas porque, con antelación, existen intereses comunes, generales, que atender convenientemente. $Y$ existen asuntos de interés general como la sanidad o la educación, porque las personas en conjunto, e individualmente consideradas, precisan de ellos. Por tanto, es la persona y sus necesidades colectivas quienes explican la existencia de instituciones supraindividuales ordenadas y dirigidas a la mejor satisfacción de esos intereses comunitarios de forma y manera que su gestión y dirección se realicen al servicio del bienestar general, integral, de todos, no de una parte, por importante y relevante que esta sea.

La buena Administración pública parte del derecho ciudadano, fundamental para más señas, a que sus asuntos comunes y colectivos estén ordenados de forma y manera que a su través se mejoren las condiciones de vida de las personas. Las Administraciones públicas, desde esta perspectiva, han de estar conducidas y manejadas por una serie de criterios mínimos, llamados de buena administración.

La buena Administración pública es un derecho ciudadano de naturaleza fundamental. ¿Por qué se proclama como derecho fundamental por la Unión Europa? Por una gran razón que reposa sobre las más altas argumentaciones del pensamiento político: en la democracia, las instituciones políticas no son de propiedad de políticos o altos funcionarios, sino que son del dominio popular, 
de los ciudadanos, de las personas de carne y hueso que día a día, con su esfuerzo por encarnar los valores cívicos y las cualidades democráticas, dan buena cuenta del temple democrático en la cotidianeidad.

Por ello, si las instituciones públicas son de la soberanía popular, de donde proceden todos los poderes del Estado, es claro que han de estar ordenadas al servicio objetivo del interés general.

Desde el punto de vista normativo, es menester reconocer que la existencia positiva de este derecho fundamental a la buena administración parte de la Recomendación núm. R (80) 2, adoptada por el Comité de Ministros del Consejo de Europa el 11 de marzo de 1980, relativa al ejercicio de poderes discrecionales por las Autoridades administrativas así como de la jurisprudencia del Tribunal de Justicia de las Comunidades Europeas y del Tribunal de Primera Instancia.

Entre el Consejo de Europa y la Jurisprudencia comunitaria, desde 1980 se fue construyendo, poco a poco, el derecho a la buena Administración pública, derecho que la Carta Europea de los Derechos Fundamentales de diciembre de 2000 recogería en el artículo 41. Más adelante, la nueva Carta Europea de los Derechos Fundamentales de 12 de diciembre de 2007, que sustituye a la anterior, recoge en los mismos términos el derecho fundamental a la buena administración pública.

Antes del comentario de este precepto, me parece pertinente señalar dos elementos de los que trae causa: la discrecionalidad y la jurisprudencia. En efecto, la discrecionalidad, se ha dicho con acierto, es el caballo de Troya del Derecho Público (Huber) por la sencilla razón de que su uso objetivo nos sitúa al interior del Estado de Derecho y su ejercicio abusivo nos lleva al mundo de la arbitrariedad y del autoritarismo.

El ejercicio de la discrecionalidad administrativa en armonía con los principios de derecho es muy importante. Tanto como que un ejercicio destemplado, al margen de la motivación que le es inherente, deviene en abuso de poder, en arbitrariedad. Y la arbitrariedad es la ausencia del derecho, la anulación de los derechos ciudadanos en relación con la administración.
Por lo que respecta a la jurisprudencia, debe tenerse en cuenta que normalmente los conceptos de elaboración jurisprudencial son conceptos construidos desde la realidad, algo que es en símismo relevante y que permite construir un nuevo derecho fundamental con la garantía del apoyo de la ciencia que estudia la solución justa a las controversias jurídicas.

El artículo 41 de la Carta constituye un precipitado de diferentes derechos ciudadanos que a lo largo del tiempo y a lo largo de los diferentes ordenamientos han caracterizado la posición central que hoy tiene la ciudadanía en todo lo que se refiere al Derecho Administrativo.

Pues bien, dicho precepto dispone:

1. Toda persona tiene derecho a que las instituciones y órganos de la Unión traten sus asuntos imparcial y equitativamente y dentro de un plazo razonable.

\section{Este derecho incluye en particular:}

- El derecho de toda persona a ser oída antes de que se tome en contra suya una medida individual que le afecte desfavorablemente.

- El derecho de toda persona a acceder al expediente que le afecte, dentro del respeto a los intereses legítimos de la confidencialidad $\mathrm{y}$ del secreto profesional y comercial.

- La obligación que incumbe a la administración de motivar sus decisiones.

3. Toda persona tiene derecho a la reparación por la Comunidad de los daños causados por sus instituciones o sus agentes en el ejercicio de sus funciones, de conformidad con los principios generales comunes a los Derechos de los Estados miembros.

4. Toda persona podrá dirigirse a las instituciones de la Unión en una de las lenguas de los Tratados y deberá recibir una contestación en esa misma lengua.

Los ciudadanos europeos tenemos un derecho fundamental a que los asuntos públicos se traten imparcialmente, equitativamente y en un tiempo razonable. Es decir, las Instituciones comunitarias han de resolver los asuntos públicos objetivamente, han de procurar ser justas 
-equitativas- $y$, finalmente, han de tomar sus decisiones en tiempo razonable.

En otras palabras, no cabe la subjetividad, no es posible la inequidad y no se puede caer en la dilación indebida para resolver. En mi opinión, la referencia a la equidad como característica de las decisiones administrativas comunitarias no debe pasar por alto. Porque no es frecuente encontrar esta construcción en el Derecho Administrativo de los Estados miembros y porque, en efecto, la justicia constituye, a la hora del ejercicio del poder público, cualquiera que sea la institución pública en la que nos encontremos, la principal garantía de acierto.

La referencia a la razonabilidad del plazo para resolver incorpora un elemento esencial: el tiempo. Si una resolución es imparcial, justa, pero se dicta con mucho retraso, es posible que no tenga sentido, que no sirva para nada. El poder se mueve en las coordenadas del espacio y del tiempo y éste es un elemento esencial que el derecho comunitario destaca suficientemente. La razonabilidad se refiere al plazo de tiempo en el que la resolución pueda ser eficaz de manera que no se dilapide el legítimo derecho del ciudadano a que su petición, por ejemplo, se conteste en un plazo en que ya no sirva para nada.

El derecho a la buena Administración pública es un derecho fundamental de todo ciudadano comunitario a que las resoluciones que dicten las instituciones europeas sean imparciales, equitativas y razonables en cuanto al fondo y al momento en que se produzcan. Dicho derecho según el citado artículo 41 incorpora, a su vez, cuatro derechos.

El primero se refiere al derecho que todo ciudadano comunitario tiene a ser oído antes de que se tome en contra suya una medida individual que le afecte desfavorablemente. Se trata de un derecho que está reconocido en la generalidad de las legislaciones administrativas de los Estados miembros como consecuencia de la naturaleza contradictoria que tienen los procedimientos administrativos en general, y en especial los procedimientos administrativos sancionadores o aquellos procedimientos de limitación de derechos. Es, por ello, un componente del derecho a la buena Administración pública que el derecho comunitario toma del Derecho Administrativo Interno.
El segundo derecho derivado de este derecho fundamental a la buena Administración pública se refiere, de acuerdo con el párrafo segundo del citado artículo 41 de la Carta de Derechos Fundamentales, al derecho de toda persona a acceder al expediente que le afecte, dentro del respeto de los intereses legítimos de la confidencialidad y del secreto profesional y comercial. Nos encontramos, de nuevo, con otro derecho de los ciudadanos en los procedimientos administrativos generales.

Claro está, existen límites derivados del derecho a la intimidad de otras personas así como del secreto profesional y comercial. Es decir, un expediente en que consten estrategias empresariales no puede consultado por la competencia en ejercicio del derecho a consultar un expediente de contratación que le afecte en un determinado concurso.

El tercer derecho que incluye el derecho fundamental a la buena administración es el más importante: el derecho de los ciudadanos a que las decisiones administrativas de la Unión Europea sean motivadas. Llama la atención que este derecho se refiera a todas las resoluciones europeas sin excepción. Me parece un gran acierto la letra y el espíritu de este precepto. Sobre todo porque una de las condiciones del ejercicio del poder en las democracias es que sea argumentado, razonado, motivado.

El poder público que se basa en la razón ética es legítimo. El que no se justifica es sencillamente arbitrario. Por eso todas las manifestaciones del poder debieran, como regla, motivarse. Su intensidad dependerá, claro está, de la naturaleza de los actos de poder. Si son reglados, la motivación será menor. Pero si son discrecionales, la exigencia de motivación será mayor. Es tan importante la motivación de las resoluciones públicas que bien puede afirmarse que la temperatura democrática de una Administración es proporcional a la intensidad de la motivación de los actos y normas administrativos.

En una sentencia más reciente, de 15 de octubre de 2010, el Tribunal Supremo del Reino de España precisa el alcance de la motivación que exige nuestra Constitución señalando que tal operación jurídica "se traduce en la exigencia de que los actos administrativos contengan una 
referencia específica y concreta de lo hechos y los fundamentos de derecho que para el órgano administrativo que dicta la resolución han sido relevantes, que permita reconocer al administrado la razón fáctica y jurídica de la decisión administrativa, posibilitando el control judicial por los tribunales de lo contencioso administrativo". Además, tal obligación de la Administración "se engarza en el derecho de los ciudadanos a una buena administración, que es consustancial a las tradiciones constitucionales comunes de los Estados miembros de la Unión Europea" que ha logrado refrendo normativo como derecho fundamental en el artículo 41 de la Carta de los Derechos Fundamentales de la Unión Europea, proclamada por el Consejo de Niza de 8/10 de diciembre de 2000, al enunciar que este derecho incluye en particular la obligación que incumbe a la Administración de motivar sus decisiones".

En el apartado tercero del precepto se reconoce el derecho a la reparación de los daños ocasionados por la actuación u omisión de las instituciones comunitarias de acuerdo con los principios comunes generales a los derechos de los Estados miembros. La obligación de indemnizar en los supuestos de responsabilidad contractual y extracontractual de la Administración está, pues, recogida en la Carta. Lógicamente, el correlato es el derecho a la consiguiente reparación cuando las instituciones comunitarias incurran en responsabilidad. La peculiaridad del reconocimiento de este derecho, también fundamental, derivado del fundamental a la buena administración, reside en que, por lo que se vislumbra, el régimen de funcionalidad de este derecho se establecerá desde los principios generales de la responsabilidad administrativa en derecho comunitario.

La cuestión del derecho a la indemnización cuando el Estado, como consecuencia del funcionamiento de sus servicios, haya provocado daños a los ciudadanos es un tema polémico. En realidad, una Administración que debe indemnizar con cantidades millonarias es una mala Administración por causar con frecuencia daños a los ciudadanos, por mucho que esté reconocido el derecho a la justa indemnización. Es mejor Administración aquella que indemniza menos porque ocasiona menos daños a los ciudadanos como consecuencia del funcionamiento de los servicios públicos en general.
El apartado cuarto del artículo 41 de la Carta de los Derechos Fundamentales de la Unión Europea dispone que toda persona podrá dirigirse a las instituciones de la Unión en una de las lenguas de los Tratados y deberá recibir una contestación en esa lengua.

Por su parte, la jurisprudencia ha ido, a golpe de sentencia, delineando y configurando con mayor nitidez el contenido de este derecho fundamental a la buena administración atendiendo a interpretaciones más favorables para el ciudadano europeo a partir de la idea de una excelente gestión y administración pública en beneficio del conjunto de la población de la Unión Europea.

Debe tenerse presente, también, que el artículo 41 del denominado Código Europeo de Buena Conducta Administrativa de 1995 es el antecedente del ya comentado artículo 41 de la carta de los Derechos Fundamentales. Es más, se trata de una fiel reproducción.

El artículo 41 de la Carta Europea de los Derechos Fundamentales de diciembre de 2007 es, ciertamente, la referencia normativa más importante que existe en el seno de la UE en la materia. Hasta el punto que el Código de Buena Conducta Administrativa de la UE, dirigido a las instituciones y a los órganos de la Unión Europea, aprobado por resolución del Parlamento Europeo de 6 de septiembre de 2001, es un instrumento de concreción precisamente del derecho fundamental a la buena administración.

En la introducción que hace el Defensor del Pueblo Europeo al Código el 5 de enero de 2005, en el epígrafe dedicado a la naturaleza jurídica, se recuerda literalmente el contenido del citado artículo 41 de la Carta y se recuerda que el Defensor del Pueblo Europeo investiga posibles casos de mala administración en las actividades de las instituciones y órganos de la Unión.

La referencia a las instituciones y órganos de la Unión debe entenderse en sentido amplio puesto que las decisiones y las declaraciones de voluntad de las instituciones y los órganos se realizan, bien unilateralmente, bien colectiva o multilateralmente, de forma y manera que la buena o la mala administración se refiere obviamente a los titulares o al titular de la potestad en cada caso. 
Según el Código, y el propio Parlamento Europeo, que se han inspirado en el informe del Defensor del Pueblo Europeo de 1997, es mala administración la que se produce cuando un organismo público no obra de conformidad con las normas o principios a los que debe obligatoriamente atenerse.

La propia Carta dispone en su artículo 43 que todo ciudadano de la UE o toda persona física o jurídica que resida o tenga su domicilio fiscal en un Estado miembro, tiene derecho a someter al Defensor del Pueblo de la Unión los casos de mala administración en la acción de las instituciones u órganos comunitarios, con exclusión del Tribunal de Justicia y del Tribunal de Primera Instancia en el ejercicio de sus funciones jurisdiccionales.

Siendo el precepto impecable, tiene un pequeño problema, que es el referido al uso del término acción para significar las actuaciones que pueden ser objeto de reclamación por haber lesionado este derecho fundamental. En lugar de acción, y para evitar problemas interpretativos, de manera que las omisiones y las inactividades también puedan desencadenar la reclamación ante el Defensor del Pueblo Europeo, debió haberse utilizado la expresión actuación, que incluye tanto decisiones expresas, como presuntas o inactividades, junto a vías de hecho.

También se recuerda en la introducción que estamos glosando, que el propio Parlamento de la UE, a través de una resolución contemporánea al mismo Código, entendió que para la determinación o comprobación de si se da un supuesto de mala administración es preceptiva la actuación del Defensor del Pueblo, dando con ello efecto al derecho de los ciudadanos a una buena administración tal y como está redactado en el artículo 41 de la Carta.

Es decir, el Defensor del Pueblo es quien en principio toma en consideración las reglas y principios establecidos en el Código al examinar los casos de mala administración.

Es tal la relevancia del derecho fundamental a la buena Administración pública, que el parlamento Europeo solicitó a la Comisión Europea que le presentara un reglamento en el que se concretaran las obligaciones que para las instituciones y órganos de la UE se derivaran de este derecho ciudadano.
Tal reglamento, se dice en la introducción del defensor del Pueblo Europeo, sería de vital importancia pues subrayaría el carácter vinculante de las reglas y principios contenidos en el Código, que así se aplicarían de forma uniforme y consistente por todas las instituciones y órganos de la UE promoviendo así la transparencia.

Esta apreciación del Defensor del Pueblo Europeo acerca de la naturaleza jurídica del contenido del Código me parece fundamental. Por una razón sencilla: si las reglas y principios del Código, de eminente carácter ético, no son de general observancia para todas las instituciones y órganos de la UE, entonces nos encontraríamos con unas consecuencias contradictorias en sí mismas.

En efecto, si el Código no tuviera consecuencias jurídicas, sus principios y normas de conducta serían meras guías voluntarias para el quehacer público en las instituciones y órganos de la UE, cuando constituyen evidentes principios básicos y fundamentales de la propia actuación administrativa. Su lesión y conculcación, en la medida en que constituyen transgresiones de la esencia misma de la función pública, de la función de servicio objetivo al interés general, deben ser sancionadas.

Si la dimensión ética de la función pública no tiene relevancia jurídica, no podremos garantizar que el comportamiento de autoridades y funcionarios se ajuste y se oriente a las más elementales reglas y criterios del servicio público.

Mientras formalmente no se apruebe dicho reglamento, el Defensor del Pueblo Europeo sigue trabajando en orden a transformar el Código en Derecho Administrativo Europeo. Tal objetivo es de gran trascendencia pues de esta manera existiría un cuerpo normativo uniforme para todas las instituciones y órganos de la UE en lo que se refiere a los principios que rigen sus relaciones con los ciudadanos.

En este sentido, la elaboración en 2012, por parte del Defensor del Pueblo Europeo, de los principios de la función pública de la UE, es una muy buena herramienta pues ayuda a dar mayor difusión y conocimiento a los principios básicos establecidos en el Código que se derivan del fundamental derecho a la buena administración 
establecido en el artículo 41 de la Carta Europea de los Derechos Fundamentales.

Por lo que se refiere al aludido Código Europeo de Buena Conducta, aprobado por el Parlamento Europeo en septiembre de 2001, poco tiempo después de la Carta Europea de los Derechos Fundamentales (diciembre de 2000 y, después, diciembre de 2007), es necesario señalar que es un instrumento magnífico para que el Defensor del Pueblo compruebe la existencia de casos de mala administración cuando así se le solicite, cumpliendo cabalmente de esta manera la función de control externo de la actuación de las instituciones y órganos de la UE que tiene encomendada. En efecto, esta función la realiza el Defensor del pueblo de acuerdo con el artículo 195 del Tratado de la Constitución Europea y con el Estatuto del propio Defensor.

La virtualidad del Código es que permite a los ciudadanos de la UE conocer en la realidad práctica en qué consiste este derecho fundamental, qué significa en concreto y en qué casos se lesiona por parte de las Autoridades de la Unión.

Aunque el Defensor del Pueblo asegura, enero de 2005, que muchos países se han inspirado en el Código para redactar los Códigos nacionales y que se ha hecho una extensa e intensa labor de difusión, lo cierto y verdad es que la simple opinión que existe en la ciudadanía acerca de la UE y de sus instituciones, es suficientemente elocuente del conocimiento real que tienen los pueblos europeos de este derecho fundamental y de sus consecuencias.

El Código señala en su artículo 1 que las instituciones y órganos de la UE, obviamente representados $\mathrm{o}$ encarnados en personas individuales o colectivas, deben respetar los principios establecidos en el Código en sus relaciones con el público. Más que respetar, lo que deben es cumplir diligentemente las obligaciones y deberes que marca el Código, y que son corolarios necesarios del derecho fundamental a la buena administración que asiste a todo ciudadano de la UE.

El Código es de aplicación, artículo 2, a todos los funcionarios y agentes de la UE de acuerdo con el Estatuto de la función pública europea y el régimen jurídico aplicable a los agentes de la
Unión. El Código utiliza el término funcionario para designar a los funcionarios de la UE en sentido estricto y a los agentes de la UE a los que es de aplicación. Funcionarios y agentes podríamos denominar al personal al servicio de la Administración pública de la UE.

Sin embargo, como precisa el precepto, el Código también se extiende, es lógico, a otras personas que trabajen para la Administración comunitaria como son los contratados en régimen de Derecho privado, expertos de Administraciones nacionales en comisión de servicios así como becarios.

Es decir, las obligaciones y deberes que se derivan del derecho fundamental a la buena administración se refieren a todas las personas que de forma directa o indirecta laboran para la Administración comunitaria, incluso a becarios y expertos nacionales en comisión de servicios. Tal extensión de las obligaciones es coherente con el alcance y significado de estas obligaciones y deberes, que gravan la conducta de aquellas personas que reciben su retribución de los fondos públicos comunitarios, con independencia de su categoría profesional.

El Código precisa, en el artículo 2, qué entiende por público, por ciudadano, por el sujeto con el que se relaciona la Administración pública comunitaria. Entiende por público a toda persona física o jurídica, independientemente de que residan o tengan su domicilio en un Estado miembro. Es decir, el autor del Código manifiesta un entendimiento muy amplio, como debe ser, del significado y alcance del término público. También en el artículo 2 precisa dos cuestiones terminológicas. Nos dice que por institución hay que entender institución y también órgano, $\mathrm{y}$ por funcionario, funcionario y agente de las Comunidades Europeas.

Por lo que se refiere al ámbito material de aplicación, el Código contiene los principios generales de buena administración aplicables a todas las relaciones entre las instituciones y el público en el artículo 3.

Capítulo aparte merecen los principios que rigen las relaciones entre los funcionarios y la institución, que se encuentran en el Estatuto de la función pública comunitaria. No se entiende bien la mención que el artículo realiza a que 
tales principios generales se pueden dispensar si existen disposiciones específicas en la materia. Pueden ser desarrollados, eso sí, pero inaplicables por existir normas específicas, parece un tanto contradictorio.

¿Es que estos principios pueden ponerse entre paréntesis o declararse inaplicables para casos específicos? ¿Los principios de ausencia de discriminación, proporcionalidad, ausencia de abuso de poder, imparcialidad, independencia, objetividad, confianza legítima, coherencia, asistencia, justicia, imparcialidad, racionalidad, cortesía, respuesta, acuse de recibo, identificación del funcionario competente, audiencia, motivación, celeridad, acceso a la información...?

También el Código, como no podía ser de otra manera, prescribe el principio de juridicidad al disponer en su artículo 4 que el funcionario actuará de conformidad con la legislación y aplicará las normas y procedimientos establecidos en la legislación comunitaria.

En concreto, el funcionario velará por que las disposiciones que afecten a los derechos o intereses de los ciudadanos estén basados en la ley y que su contenido cumpla la legislación. Se trata, pues, de la enunciación del principio de legalidad en su versión más formal. Salvo que interpretemos el término legislación en un sentido amplio, que no es fácil, tal y como está redactado, podríamos colegir que hay una referencia al derecho. El principio de juridicidad se refiere a la ley y al derecho.

En el artículo 5 empiezan las referencias a los principios generales de buena conducta administrativa, que constituyen un corolario necesario, no se puede perder de vista, del derecho fundamental a la buena administración del que disponen los ciudadanos de la UE.

El primero de estos principios generales es el de igualdad o, en términos negativos, ausencia de discriminación. El principio se plantea en el marco de la tramitación de las solicitudes del público y en el ámbito de la toma de decisiones. En ambos casos, el funcionario debe garantizar el principio de igualdad de trato, que implica que los ciudadanos que se encuentren en la misma situación procedimental serán tratados de igual manera, de manera similar dice el Código. En el caso de que se produzca alguna diferencia de trato, esta deberá ser justificada, motivada convenientemente en función, dice el Código, de las características pertinentes objetivas del caso. Es decir, la motivación debe estar fundada sobre la realidad, sobre las características pertinentes del caso y, lo que es más importante, debe hacerse objetivamente.

El contenido del principio de ausencia de discriminación, en particular, implica que el funcionario evitará toda discriminación injustificada entre miembros del público por razones de nacionalidad, sexo, raza, color, origen étnico o social, características genéticas, lengua, religión o creencias, opiniones políticas o de cualquier tipo, pertenencia a una minoría nacional, propiedad, nacimiento, discapacidad, edad u orientación sexual. Estas listas tan largas deberían evitarse pues en el futuro no sería extraño que surja una nueva causa de discriminación por lo que es mejor usar fórmulas más amplias que den cabida a cualquier forma de discriminación por la causa que fuere.

Un principio general, también del Derecho, es el de proporcionalidad. El Código en su artículo 6 lo define así: al adoptar decisiones el funcionario garantizará que las medidas sean proporcionales al fin perseguido, evitando toda forma de restricción de los derechos de los ciudadanos así como la imposición de cargas cuando éstas y aquellas no sean razonables con respeto al objeto perseguido.

Además, al adoptar decisiones, el funcionario respetará el justo equilibrio entre los intereses individuales y el interés público general. Es decir, las decisiones deben estar en consonancia con el fin establecido en las normas que le sirven de cobertura y con el interés general concreto.

El interés general al que deben estar supeditadas todas las decisiones de los funcionarios tiene dos dimensiones. Por un lado, los principios y criterios del Estado social y democrático de Derecho que han de estar proyectados en las normas que sirven de cobertura a dichas medidas. Y, por otro, la realidad concreta en que se encarna el interés general porque el interés general solo tiene sentido para el Estado de Derecho si se nos presenta de forma concreta y con la motivación y justificación que sea menester según el grado de discrecionalidad ínsito en la potestad desde la que se dicta la decisión. 
Igualmente, la referencia que hace al justo equilibrio entre el interés particular y el interés general debe entenderse como operación de contraste jurídico realizada sobre el caso concreto, sobre la realidad. En otras palabras, es muy adecuada esta expresión de justo equilibrio que utiliza el autor del Código en esta materia porque, en mi opinión, constituye un fiel reflejo de una de las características que mejor define el sentido de las ciencias sociales en este tiempo: el pensamiento compatible o complementario.

El poder en el Estado de Derecho sólo tiene sentido si se ejerce al servicio objetivo del interés general. Por eso, el artículo 7 se refiere al principio de ausencia de abuso de poder. Precisamente porque el poder público es una institución que se justifica en la medida en que se dirige a posibilitar el libre y solidario desarrollo de las personas.

La persona es el centro y la raíz del Estado y los poderes públicos que las normas atribuyen a los titulares, individuales o colectivos; se justifican en la medida en que su ejercicio vaya dirigido a la mejora de las condiciones de vida de los ciudadanos, no de las condiciones de vida de los gobernantes. Por eso el artículo 7 dispone con toda claridad que los poderes se ejercerán únicamente de acuerdo con la finalidad para la que han sido otorgados por las disposiciones pertinentes, evitando el uso de dichas potestades para objetivos sin fundamento legal o que no estén motivados por un interés público.

Es decir, el poder debe ejercerse en función del fin previsto en la norma, que no puede ser otro que de interés general, obviamente, y también por razones de interés público explícitas, que obviamente habrán de argumentarse convenientemente. Insisto, en los casos en que el poder se funde sobre razones de interés general, éste ha de estar perfectamente delimitado en la realidad y argumentado en lo concreto suficientemente.

La imparcialidad y la independencia son también dos principios básicos que deben distinguir la actuación de los funcionarios comunitarios $y$, por ende, a las mismas instituciones europeas.

En virtud de la imparcialidad, dice el artículo 8 que el funcionario se abstendrá de toda acción arbitraria que afecte adversamente a los ciudadanos, así como de cualquier trato preferente por cualesquiera motivos. En mi opinión, una interpretación literal, pegada a la letra de este parágrafo del precepto, nos llevaría a una conclusión absurda: que una acción arbitraria que no afecte negativamente a los ciudadanos de la Unión podría ser posible.

Una acción arbitraria es una acción irracional y, como ya sabemos, el quehacer administrativo de la unión Europea, por mor del artículo 41 de la Carta, debe estar motivado. Y una acción motivada excluye radicalmente la arbitrariedad que es, insisto, contraria a la misma Carta y, por tanto, como más adelante comentaremos, al artículo 18 del Código. La imparcialidad exige que no se tome partido a favor de ninguna persona, física o jurídica, porque todas son iguales ante la ley y hacia todas se debe ofrecer el mismo y correcto trato.

A la independencia de los funcionarios se refiere el artículo 8 en su último parágrafo en estos términos: "la conducta del funcionario nunca estará guida por intereses personales, familiares o nacionales, ni por presiones políticas. El funcionario no participará en una decisión en la que él mismo, o un familiar cercano, tenga intereses económicos".

El funcionario sólo debe guiarse por razones de interés general. Además, cuando advierta que una determinada decisión a la que está llamado a participar colisiona con asuntos personales o familiares, deberá abstenerse.

Corolario necesario del derecho a una buena Administración pública es el principio de objetividad. La subjetividad suele estar en la base de la mala administración, de las decisiones arbitrarias, que son todas aquellas en las que existe una ausencia de racionalidad. El principio de objetividad en el Código está redactado, artículo 9, en términos de principio de relevancia, que es una consecuencia concreta de la objetividad: "al adoptar sus decisiones, el funcionario tendrá en cuenta los factores relevantes y otorgará a cada uno de los mismos su propia importancia en la decisión, excluyendo de su consideración todo elemento irrelevante".

Si entendemos que la objetividad supone racionalidad porque lo objetivo es lo que se puede argumentar desde la lógica, lo que se 
puede fundar desde las más elementales reglas de la razón, el principio de relevancia reclama al funcionario que identifique el o los asuntos relevantes en cada decisión, resolviendo desde esos parámetros y excluyendo las cuestiones accesorias o tangenciales.

Este principio tiene mucha importancia porque hasta ahora en muchos casos los funcionarios resolvían o dictaban medidas o decisiones administrativas por razones subjetivas, o por sinrazones, basándose en argumentos peregrinos o accesorios.

Los precedentes administrativos siempre han sido muy importantes en la praxis administrativa, así como el principio de confianza legítima, corolario necesario del principio de buena fe proyectado sobre el derecho administrativo. Es lógico que haya una cierta continuidad en las políticas públicas y que los criterios de regularidad y, valga la reiteración, de continuidad sigan fundando el régimen de los servicios públicos así como de los llamados servicios de interés general.

Las decisiones administrativas gozan de la presunción de legitimidad, que exige, cuando se dictan al amparo de potestades discrecionales, una debida justificación. En otras palabras, que la expresiones de voluntad de la Administración, también de la comunitaria, generan razonables expectativas que, salvo por acreditadas razones de interés general, habrán de ser cumplidas por los funcionarios.

El artículo 10 del Código se ocupa de este tema al señalar que el funcionario será coherente en su propia práctica administrativa, así como en la actuación administrativa de la institución, lo que implica que el funcionario debe respetar el precedente administrativo existente en la institución, salvo que existan razones fundadas, en cuyo caso deberá, dice el artículo glosado, expresar ese fundamento por escrito.

Coherencia, precedente administrativo, racionalidad, son términos relacionados con el quehacer de las Administraciones públicas, que en sus actuaciones no disponen, ni mucho menos, de la autonomía de las personas físicas, pues están vinculadas a las normas y a los procedimientos.
El principio de confianza legítima está contemplado también en este precepto, concretamente en el párrafo segundo: el funcionario respetará las legítimas y razonables expectativas de sus actuaciones ante los ciudadanos. El límite de este principio se encuentra en la legitimidad y la racionalidad de las expectativas generadas. Si éstas fueran ilegales o arbitrarias, nos encontraríamos con una grave lesión de este principio, que el Código denomina "legítimas expectativas, consistencia y asesoramiento".

En los dos primeros párrafos de este precepto, el Código se refiere a la confianza legítima y en el tercero al principio de asesoramiento, que es un principio que se deriva de la centralidad del ser humano y, por ende, del derecho fundamental a la buena administración: si fuera necesario, el funcionario asesorará a los ciudadanos acerca de cómo debe presentarse un asunto de su competencia, así como sobre el modo en que se debe actuar mientras se trate ese asunto.

Consecuencia de la equidad que el artículo 41 de la Carta exige a los funcionarios y a las instituciones en el principio de justicia, establecido en el artículo 11: "el funcionario actuará de manera imparcial, justa y razonable". Imparcialidad, justicia y racionalidad, tres principios que conforman el alma de la Administración, están indeleblemente unidos entre sí.

La buena Administración pública exige un trato cortés, educado, de los funcionarios a los ciudadanos, y viceversa también, evidentemente. El artículo 12 trata este principio denominado de cortesía, principio que es tratado en un sentido muy amplio, pues bajo la rúbrica general de cortesía, se hace referencia a la diligencia, a la corrección y a la accesibilidad a los ciudadanos. Quizá fuera más adecuado referirse al principio de servicio al ciudadano, que es más general. La referencia a la diligencia alude a trabajo bien hecho, a trabajo realizado con profesionalidad, lo que nos llevaría también a enunciar, cosa que el Código no hace, a este principio, que es desde luego un principio de ética muy importante, tanto que es capital y central para comprender el sentido y alcance del sentido ético del quehacer administrativo de los funcionarios de la UE. 
En este punto, el autor del Código ubica el deber de respuesta, que es una obligación, legal por supuesto, pero que tiene un fuerte contenido ético. Así, podemos leer en el párrafo primero de este artículo que al responder a la correspondencia, llamadas telefónicas y correo electrónico, el funcionario tratará en la mayor medida posible de ser servicial y responderá a las preguntas que se le plantean de la manera más completa y exacta posible.

En efecto, el principio de servicio imprime una forma de trabajar de los funcionarios a disposición de los ciudadanos, por lo que su entero quehacer administrativo debe estar presidido por este principio, de manera que en sus relaciones con los ciudadanos, también, como es lógico, con sus subordinados, siempre debe conducirse con este sentido de servicio permanente.

Una consecuencia del principio de servicio es que al ciudadano deben ahorrársele todos los trámites innecesarios. El párrafo segundo del artículo 12 dispone que si el funcionario advierte que un asunto sometido a su consideración no es de su competencia, deberá orientar al ciudadano en cuestión al funcionario realmente competente. Sin embargo, sería más sencillo para el ciudadano que fuera el propio funcionario el que internamente remitiera el asunto al competente haciéndoselo saber así al ciudadano solicitante. Esta solución me parece más coherente con el principio de servicio porque indicar al ciudadano a quién debe dirigirse supone tantas veces continuar un peregrinaje administrativo, a veces sin fin.

¿Y si el funcionario comete un error que afecta negativamente los derechos o intereses legítimos de un ciudadano? El párrafo tercero del artículo 12 viene a dar por bueno ese inteligente dicho que reza así: rectificar es de sabios. En estos casos, el artículo señala que el funcionario presentará sus excusas, tratará de corregir los efectos negativos resultantes de su error de la forma más rápida posible e informará al interesado de las posibilidades de recurso de conformidad con el artículo 19 del código.

En consonancia con el artículo 41 de la Carta, el Código garantiza que los ciudadanos que se dirijan a las instituciones comunitarias en una de las lenguas del Tratado recibirán una respuesta en dicha lengua (artículo 13). En este mismo sentido, de facilitar a los ciudadanos los trámites ante la UE, el artículo 14 del Código dispone que de toda reclamación o petición de los ciudadanos ante las instituciones de la UE se entregará a dichos ciudadanos un acuse de recibo en un plazo máximo de dos semanas, salvo que en este plazo se pueda enviar una contestación pertinente o salvo en los casos en los que las reclamaciones o peticiones resulten impertinentes, bien por su número excesivo o por ser repetitivas o absurdas.

El acuse de recibo, señala el párrafo segundo de este precepto, especificará el nombre y número de teléfono del funcionario competente para tramitar el asunto así como del servicio al que dicho funcionario pertenece. Tal disposición permite que el derecho que asiste a todo ciudadano a conocer el estado de los procedimientos administrativos en que sea interesado sea efectivo, pues de esta manera los ciudadanos pueden relacionarse con el funcionario responsable y preguntar sobre el curso de sus reclamaciones o pedidos.

El principio de servicio al ciudadano y de facilitación de los trámites se concreta en el artículo 15 del Código, en el que se establece que si un escrito o reclamación es dirigida a una institución que no sea competente para su tramitación, dicha unidad deberá ponerla en conocimiento del órgano competente advirtiendo de tal circunstancia al ciudadano solicitante, indicándole además la identidad y el teléfono del funcionario competente al que se ha hecho llegar el expediente. Una vez que el funcionario competente empiece la instrucción del expediente, deberá, en caso de existir errores u omisiones en la solicitud, comunicarlo al interesado facilitándole que pueda subsanar dichos errores u omisiones.

El derecho de audiencia y de hacer observaciones durante el procedimiento se encuentra reconocido en el artículo 16 del Código. El funcionario deberá garantizar este derecho, facilitando, además, que se respeten los derechos de defensa del interesado porque en el procedimiento administrativo, como señalamos con anterioridad, rige el derecho a la tutela administrativa efectiva.

El derecho de audiencia se complementa, como corolario necesario, con el derecho que asiste a todo ciudadano interesado en el procedimiento administrativo, siempre que la decisión afecte a sus derechos e intereses, de hacer observaciones 
y comentarios por escrito y, de ser necesario, a formular observaciones orales con anterioridad a la adopción de la decisión administrativa.

El derecho a la buena Administración pública del artículo 41 de la Carta Europea de los Derechos Fundamentales, incluye el derecho a que las decisiones se adopten en plazo razonable. Por eso, el artículo 17 del Código reconoce este derecho a la decisión en plazo razonable, sin demoras y, en caso de ser necesario, antes de un período de dos años a contar desde el momento en el que conste la recepción del escrito de solicitud.

Este mismo derecho, sigue diciendo el precepto, se aplica también a la respuesta a cartas de los ciudadanos dirigidas a las instituciones comunitarias así como a las respuestas a notas administrativas que el funcionario haya enviado a sus superiores jerárquicos solicitando instrucciones relativas a las decisiones que deba adoptar. En el parágrafo segundo del artículo se contemplan los casos de expedientes complejos en los que no sea posible resolver en el plazo anteriormente indicado. En estos casos, el Código dispone que el funcionario competente informe al ciudadano autor del escrito en el más breve plazo de tiempo posible, significando que en estos casos la decisión administrativa deberá comunicarse a dicho ciudadano en el plazo más breve posible.

El derecho a la buena Administración pública del artículo 41 de la Carta incluye la obligación para los funcionarios de motivar sus decisiones. Este derecho-deber a la motivación de las decisiones, uno de los más importantes como señalamos con anterioridad, está regulado en el artículo 18.

En este precepto se señala que toda decisión de las instituciones de la UE que pueda afectar desfavorablemente los derechos e intereses de los ciudadanos, deberá indicar los motivos en que esté basada, exponiendo claramente los hechos pertinentes y el fundamento jurídico de la decisión. En este sentido, el funcionario, según dispone el párrafo segundo del artículo, evitará adoptar decisiones basadas en motivos breves o genéricos que no contengan un razonamiento concreto.

Es decir, la motivación debe ser clara, concreta y con expresa referencia al supuesto individual al que se refiere. Cuando las decisiones afecten a un número elevado de ciudadanos, según el parágrafo tercero del artículo 18, y no sea, por tanto, posible comunicar detalladamente los motivos de la decisión, se procederá a partir de respuestas normalizadas aunque el funcionario, en un momento posterior, facilitará al ciudadano que expresamente lo solicite una motivación individual.

El principio de servicio a los ciudadanos incluye, es lógico, que se les facilite la información relativa a los recursos y reclamaciones, con mención de las autoridades ante las que se deben presentar así como los plazos para hacerlo, que están a su disposición frente a las resoluciones administrativas que afecten desfavorablemente los derechos e intereses de los ciudadanos, tal y como dispone el artículo 19 del Código.

Las notificaciones de las decisiones que afecten desfavorablemente los derechos e intereses de los ciudadanos, deberán ser comunicadas inmediatamente a su adopción, absteniéndose el funcionario de comunicar dichas resoluciones a otras fuentes antes que al ciudadano afectado, tal y como prescribe el artículo 20.

El artículo 21 establece el principio del respeto a la vida privada y a la integridad de las personas, a la protección de los datos personales con ocasión de los procedimientos y decisiones administrativas, materia en la que se han de observar las normas comunitarias dictadas al efecto, evitando el funcionario especialmente el tratamiento de datos personales con fines no justificados o la transmisión de tales datos a personas no autorizadas.

El acceso a la información es otra manifestación del principio y del derecho a la buena administración. Tal materia ocupa el artículo 22 del código, que impone a los funcionarios el deber de facilitar a los ciudadanos la información que soliciten, incluida la información acerca de cómo iniciar un procedimiento en el ámbito de su competencia.

Por supuesto, la información suministrada por el funcionario debe ser clara y comprensible. Si la información se solicita oralmente y es demasiado complicada o demasiado extensa, el funcionario, párrafo segundo del artículo 22, indicará a la persona afectada que formule la petición por escrito. En caso de que la materia objeto de la 
información sea confidencial, el funcionario, párrafo tercero, deberá indicar al peticionario los motivos por los que no puede comunicar dicha información. Cuándo se soliciten informaciones de las que no sea competente, el funcionario que reciba tales peticiones deberá indicar al solicitante de las mismas el nombre y teléfono del funcionario competente $y$, si fuera el caso, los datos de la institución competente o responsable para tratar dicha información (párrafo cuarto).

Finalmente, el funcionario, dependiendo del tema de la solicitud, dirigirá a la persona solicitante de la información al servicio de información al público de la institución competente (párrafo quinto). El principio de servicio y de facilitación aconsejaría en este supuesto que sea el propio funcionario el que internamente haga llegar la solicitud de información a donde corresponda, comunicando dicha circunstancia al solicitante.

En el mismo sentido, el artículo 23 se refiere al acceso de los ciudadanos a los documentos y archivos administrativos, señalando que, en estos casos, dichas solicitudes se tratarán de acuerdo con el derecho comunitario.

El derecho de acceso a la información sólo será efectivo si los archivos en los que obran las informaciones están ordenados y bien tratados. Por eso el artículo 24 manda a los departamentos de las instituciones a mantener los adecuados archivos de correspondencia de entrada y salida de los documentos que reciban y de las medidas que se adopten.

Finalmente, cada institución procurará informar a los ciudadanos de sus derechos $y$, cuando sea posible, lo hará electrónicamente, publicándolo en su página web. Además, la propia Comisión europea, en nombre de todas las instituciones de la UE, publicará y distribuirá el Código entre los ciudadanos en forma de folleto (artículo 25).

El Defensor del Pueblo Europeo es la institución competente para conocer de las reclamaciones frente a lesiones o incumplimientos establecidos en este Código, dice el artículo 26, por lo que adquiere una gran relevancia en orden a la garantía del derecho a la buena administración y a la preservación de los principios éticos de la función pública en Europa.
Una cuestión central en la materia es la referente a la autoridad que ha de investigar las denuncias de mala administración de las instituciones europeas. Pues bien, de acuerdo con el artículo 195 del Tratado de Roma y del Estatuto del Defensor del Pueblo, resulta que esta tarea es de competencia del propio Defensor del Pueblo. Una definición de mala administración nos la ofrece el informe del Defensor del año 1997: "se produce mala administración cuando un organismo no obra de acuerdo con las normas o principios a los que debe estar sujeto".

Definición que es demasiado general e imprecisa, por lo que habrá de ceñirse a los parámetros jurídicos señalados en el artículo 41 de la Carta, de manera que habrá de observarse, además de la lesión de las normas del servicio de los principios generales que presiden la actividad de las instituciones públicas, si efectivamente se contraviene la equidad, la imparcialidad, la racionalidad en los plazos, la contradicción, la motivación, la reparación o el uso de las lenguas oficiales.

En fin, el reconocimiento a nivel europeo del derecho fundamental a la buena Administración pública constituye, además, un permanente recordatorio a las Administraciones públicas de que su actuación ha de realizarse con arreglo a unos determinados cánones o estándares que tienen como elemento medular la posición central del ciudadano. Posición central del ciudadano que ayudará a ir eliminando de la praxis administrativa toda esa panoplia de vicios y disfunciones que conforman la llamada mala administración.

\section{PRINCIPIOS DE LA BUENA ADMINISTRACIÓN Y DERECHOS CONCRETOS QUE COMPONEN EL DERECHO FUNDAMENTAL}

La centralidad del ciudadano para la Administración pública y su posición estelar en el nuevo Derecho Administrativo, han permitido que, en la Unión Europea, la Carta Europea de los Derechos Fundamentales haya reconocido el derecho fundamental de los ciudadanos europeos a la buena Administración pública.

Este derecho, como hemos señalado, se concreta en una determinada manera de administrar lo público caracterizada por la 
equidad, la objetividad y los plazos razonables. En este marco, en el seno del procedimiento administrativo, la proyección de este derecho ciudadano básico, de naturaleza fundamental, supone la existencia de un elenco de principios generales y de un repertorio de derechos ciudadanos que adquieren una relevancia singular. Estos derechos componen, junto con las consiguientes obligaciones, el estatuto jurídico del ciudadano ante la Administración pública.

En el marco del respeto al Ordenamiento jurídico en su conjunto, la Administración pública sirve con objetividad al interés general y actúa, especialmente en sus relaciones con los ciudadanos, de acuerdo con los siguientes principios, que son corolarios del derecho fundamental a la buena Administración pública:

1. Principio de juridicidad, en cuya virtud toda la actuación administrativa se somete plenamente al ordenamiento jurídico del Estado.

2. Principio de servicio objetivo a los ciudadanos, que se proyecta a todas las actuaciones administrativas y de sus agentes y que se concreta en el profundo respeto a los derechos e intereses legítimos de los ciudadanos.

3. Principio promocional de los poderes públicos, expresado en la creación de las condiciones para que la libertad y la igualdad de las personas y de los grupos en que se integran sean reales y efectivas, removiendo los obstáculos que impidan su cumplimiento y fomentando igualmente la participación.

4. Principio de racionalidad, que se extiende especialmente a la motivación y argumentación que debe servir de base a la entera actuación administrativa.

5. Principio de igualdad de trato, por el que los ciudadanos que se encuentren en la misma situación serán tratados de manera igual, garantizándose, con expresa motivación en los casos concretos, las razones que puedan aconsejar la diferencia de trato, prohibiéndose expresamente toda discriminación injustificada hacia los ciudadanos.
6. Principio de eficacia, en cuya virtud las actuaciones administrativas se realizarán en el marco de los objetivos establecidos en cada ente público. Especialmente las autoridades buscarán que los procedimientos y las medidas adoptadas logren su finalidad y, para ello, removerán de oficio los obstáculos puramente formales, evitarán el silencio administrativo, las dilaciones y los retardos.

7. Principio de publicidad de las normas, de los procedimientos y del entero quehacer administrativo en el marco del respeto del derecho a la intimidad y de las reservas que por razones acreditadas de confidencialidad o interés general sean pertinentes en cada caso, en los procedimientos para el dictado de actos administrativos.

En especial, las autoridades darán a conocer a los ciudadanos y a los interesados, de forma sistemática y permanente, aun sin mediar petición alguna, sus actos, contratos y resoluciones, mediante comunicaciones, notificaciones y publicaciones, incluyendo el empleo de tecnologías que permitan difundir de forma masiva tal información.

8. Principio de seguridad jurídica, de previsibilidad y certeza normativa, por los cuales la administración se somete al derecho vigente en cada momento, sin que pueda variar arbitrariamente las normas jurídicas.

9. Principio de proporcionalidad: las decisiones administrativas serán proporcionadas al fin previsto en el ordenamiento jurídico, se dictarán en un marco de justo equilibrio entre el interés general y el interés particular y se evitará limitar los derechos de los ciudadanos a través de la imposición de cargas o gravámenes irracionales o incoherentes con el objetivo establecido.

10.Principio de ejercicio normativo del poder, en cuya virtud los poderes se ejercerán, única y exclusivamente, para la finalidad prevista en las normas de otorgamiento, evitándose especialmente el abuso de poder, bien sea para objetivos distintos 
de los establecidos en las disposiciones generales o en contra del interés general.

11. Principio de imparcialidad e independencia: el personal al servicio de la administración pública deberá abstenerse de toda actuación arbitraria o que ocasione trato preferente por cualquier motivo y actuar en función del servicio objetivo al interés general, prohibiéndose la participación de dicho personal en cualquier asunto en el que él mismo, o personas o familiares próximos, tengan cualquier tipo de intereses o pueda existir conflicto de intereses.

12. Principio de relevancia, en cuya virtud las actuaciones administrativas habrán de adoptarse en función de los aspectos más relevantes, sin que sea posible, como fundamento de la decisión que proceda, valorar únicamente aspectos de escasa consideración.

13. Principio de coherencia: las actuaciones administrativas serán congruentes con la práctica y los antecedentes administrativos salvo que, por las razones que se expliciten por escrito, sea pertinente en algún caso apartarse de ellos.

14.Principio de buena fe, en cuya virtud las autoridades y los particulares presumirán el comportamiento legal de unos y otros en el ejercicio de sus competencias, derechos y deberes

15.Principio de confianza legítima, en cuya virtud la actuación administrativa será respetuosa con las expectativas que razonablemente haya generado la propia administración en el pasado.

16.Principio de asesoramiento: el personal al servicio de la Administración pública deberá asesorar a los ciudadanos sobre la forma de presentación de las solicitudes y su tramitación.

17.Principio de responsabilidad, por el que la Administración responderá de las lesiones en los bienes o derechos de los ciudadanos ocasionados como consecuencia del funcionamiento de los servicios públicos o de interés general. Las autoridades y sus agentes asumirán las consecuencias de sus actuaciones de acuerdo con el ordenamiento jurídico. Igualmente, la Administración pública rendirá cuentas de sus actuaciones y publicará las evaluaciones de sus unidades.

18.Principio de facilitación: los ciudadanos encontrarán siempre en la Administración las mayores facilidades para la tramitación de los asuntos que les afecten, especialmente en lo referente a identificar al funcionario responsable, a obtener copia sellada de las solicitudes, a conocer el estado de tramitación, a enviar, si fuera el caso, el procedimiento al órgano competente, a ser oído y a formular alegaciones o a la referencia a los recursos susceptibles de interposición.

19.Principio de celeridad, en cuya virtud las actuaciones administrativas se realizarán optimizando el uso del tiempo, resolviendo los procedimientos en plazo razonable que, en todo caso, no podrá superar los dos meses a contar desde la presentación de la solicitud en cualquier registro público. En especial, las autoridades impulsarán oficiosamente los procedimientos e incentivarán el uso de las tecnologías de la información y las comunicaciones a los efectos de que los procedimientos se tramiten con diligencia y sin dilaciones injustificadas.

20.Principio de transparencia y acceso a la información de interés general: el funcionamiento, actuación y estructura de la Administración ha de ser accesible a todos los ciudadanos, que pueden conocer la información generada por las administraciones públicas y las instituciones que realicen funciones de interés general.

21.Principio de protección de la intimidad: de forma que el personal al servicio de la Administración pública que maneje datos personales respetará la vida privada y la integridad de las personas, prohibiéndose el tratamiento de los datos personales con fines no justificados y su transmisión a personas no autorizadas. 
22.Principio de ética, en cuya virtud todo el personal al servicio de la Administración pública así como los ciudadanos en general han de actuar con rectitud, lealtad y honestidad.

23.Principio de debido proceso: las actuaciones administrativas se realizarán de acuerdo con las normas de procedimiento y competencia establecidas en la Constitución, con plena garantía de los derechos de representación, defensa y contradicción.

24.Principio de cooperación: todos los órganos y entidades administrativos deben prestarse asistencia mutua y respetar el ejercicio de las respectivas competencias.

El derecho general fundamental de los ciudadanos a una buena Administración pública finalmente, se puede concretar, entre otros, en los siguientes derechos que lo componen, que los ciudadanos podrán hacer valer ante los Tribunales del orden administrativo o judicial.

1. Derecho a la motivación de las actuaciones administrativas: todas las actuaciones de la Administración deberán estar amparadas en razonamientos inteligibles para sus destinatarios. Cuanto más extensa e intensa sea la discrecionalidad desde la que opere la Administración pública, la motivación será proporcionada al alcance del poder administrativo del que dispone la propia Administración.

2. Derecho a la tutela administrativa efectiva: durante la sustanciación del procedimiento administrativo, la propia Administración evitará que el ciudadano interesado pueda encontrarse en situación de indefensión.

3. Derecho a una resolución administrativa en plazo razonable: las Autoridades administrativas resolverán los expedientes que obren en su poder en plazos que permitan una defensa razonable y adecuada de los ciudadanos, en el marco de los medios materiales y personales con los que cuente en cada caso la Administración pública.
4. Derecho a una resolución justa de las actuaciones administrativas. Efectivamente, como la Administración pública está sometida a la Ley y al derecho, también en sede administrativa, la resolución que se adopte en cada procedimiento debe estar amparada por la Ley y por el derecho. Debe ser justa, debe ser equitativa.

5. Derecho a presentar por escrito o de palabra peticiones de acuerdo con lo que se establezca en las normas, en los registros físicos o informáticos. La forma de relación del ciudadano con la Administración debe ser elegida por el propio ciudadano y la Administración debe estar dispuesta a atender a las personas en función del medio de relación que éstas entiendan de su preferencia.

6. Derecho a respuesta oportuna y eficaz de las autoridades administrativas. La Administración pública debe responder siempre al ciudadano. No sólo porque éste tenga derecho a respuesta de la Administración, que lo tiene, sino porque el ciudadano tiene derecho igualmente a que la respuesta sea la que tiene que ser, la que en el momento pertinente es la apropiada y adecuada. Además, la respuesta tiene que producirse en el tiempo pertinente para que la respuesta tenga sentido para el Derecho.

7. Derecho a no presentar documentos que ya obren en poder de la administración pública. En efecto, las posibilidades de intercomunicación a través de las TIC de los registros de las distintas Administraciones públicas, deben hacer posible que entre ellas se intercambien todos los documentos que, obrando en su poder, sean necesarios para que las personas tramiten sus correspondientes procedimientos administrativos.

8. Derecho a ser oído siempre antes de que se adopten medidas que les puedan afectar desfavorablemente. El derecho de audiencia es una garantía básica de que las decisiones que puedan adoptarse en contra de los ciudadanos se produzcan de forma contradictoria 
9. Derecho de participación en las actuaciones administrativas en que tengan interés, especialmente a través de audiencias y de informaciones públicas. En todos los procedimientos administrativos en los que se van a adoptar medidas que afectan a ciudadanos, éstos podrán personarse, a través de audiencias o de informaciones públicas, según cual sea la naturaleza de la decisión.

10.Derecho a una indemnización justa en los casos de lesiones de bienes o derechos como consecuencia del funcionamiento de los servicios de responsabilidad pública. La garantía patrimonial, consecuencia del Estado de Derecho, asegura que toda persona a la que la Administración, como consecuencia del funcionamiento de los servicios de su responsabilidad, haya lesionado sus derechos o bienes, disponga de una justa indemnización.

11. Derecho a servicios públicos y de interés general de calidad. Los servicios de responsabilidad pública deben ofrecer a los usuarios determinados patrones o estándares concretos de calidad, que se medirán periódicamente y se pondrán en conocimiento de los usuarios, para que estos estén lo mejor informados posible.

12. Derecho a elegir los servicios de interés general de su preferencia. Cuando sea posible, sobre todo en el marco de los servicios económicos, los usuarios podrán elegir los servicios de su preferencia en el contexto del principio de mejores servicios a mejores precios.

13. Derecho a opinar sobre el funcionamiento de los servicios de responsabilidad administrativa. Los ciudadanos, los usuarios de los servicios, una vez que conozcan el grado de calidad de la prestación de los mismos, podrán expresar en la forma en que estimen conveniente sus puntos de vista y opiniones de cara a una mejor prestación de los mismos.

14.Derecho a conocer las obligaciones y compromisos de los servicios de responsabilidad administrativa. Los servicios de responsabilidad pública deben publicar periódicamente, por supuesto en lugares visibles a los usuarios, las tablas de derechos de los usuarios así como las obligaciones del prestador, expresados en la forma más concreta y detallada posible.

15. Derecho a formular alegaciones en cualquier momento del procedimiento administrativo. Con independencia de las audiencias e informaciones públicas que estén previstas en los procedimientos administrativos, la persona interesada podrá formular las alegaciones que estime pertinentes, siempre convenientemente argumentadas, en cualquier momento del procedimiento, incluso antes de su inicio.

16. Derecho a presentar quejas, reclamaciones y recursos ante la administración. La naturaleza contradictoria del procedimiento administrativo garantiza que, una vez dictada la correspondiente resolución, está sea objeto de queja, reclamación o recurso ante las autoridades administrativas o ante las judiciales.

17.Derecho a interponer recursos ante la autoridad judicial sin necesidad de agotar la vía administrativa previa, de acuerdo con lo establecido en las leyes. Más en concreto, el ciudadano interesado, si así lo prefiere, podrá acudir directamente ante el poder judicial sin esperar a agotar la vía administrativa.

18.Derecho a conocer las evaluaciones de los entes públicos y a proponer medidas para su mejora permanente. Las evaluaciones periódicas del desempeño de los entes públicos deben ser puestas a disposición de los ciudadanos, de manera que sean conocidas por todos, especialmente por quienes tiene más relación con dicha entidad $\mathrm{y}$, así, puedan los ciudadanos proponer medidas o iniciativas dirigidas a la mejora del funcionamiento de las oficinas públicas.

19.Derecho de acceso a los expedientes administrativos que les afecten en el marco del respeto al derecho a la intimidad y a las declaraciones motivadas de reserva que en todo caso habrán de concretar el interés general al caso concreto. Los ciudadanos 
interesados podrán acceder a la información de interés general que precisen como consecuencia de la obligación de servicio objetivo al interés general que grava la actuación de todos los entes públicos.

20.Derecho a una ordenación racional y eficaz de los archivos públicos. El acceso a la información de interés general será real y efectivo si los archivos de las oficinas de las entidades públicas están convenientemente ordenados y tratados, especialmente a través de las posibilidades técnicas que ofrecen las TIC.

21.Derecho de acceso a la información de interés general. Asimismo, las instituciones privadas que manejen fondos públicos, incluidos los concesionarios de servicios públicos, organizaciones no gubernamentales 0 partidos políticos, sindicatos o patronales, están igualmente obligados, para esos casos, a facilitar la información que se solicite.

22.Derecho a copia sellada de los documentos que presenten a la Administración pública. Todo ciudadano, para poder en su caso iniciar un procedimiento administrativo o una determinada solicitud ante la Administración pública, recibirá copia sellada de tal actuación ante las administraciones públicas.

23.Derecho a ser informado y asesorado en asuntos de interés general. Los ciudadanos tienen derecho a que en las oficinas públicas quienes allí laboran asesoren e informen cordialmente acerca de los trámites u otras cuestiones de interés general que sean planteadas por los ciudadanos. Por eso, en todas las oficinas administrativas debe haber organigramas con las competencias de todas los entes públicos del país, pertenezcan al ámbito administrativo que pertenezcan.

24.Derecho a ser tratado con cortesía y cordialidad. Todo ciudadano, por el hecho se ser persona, debe ser tratado como tal por los servidores públicos que laboran en las dependencias públicas, de modo especial con los ciudadanos con menos conocimientos o aquellos que precisen mayores atenciones.

25.Derecho a conocer el responsable de la tramitación del procedimiento administrativo. Cuando se inicia un procedimiento administrativo, en la copia sellada que se entrega al ciudadano interesado, se hará constar la identidad del servidor público responsable de la tramitación de dicho expediente.

26.Derecho a conocer el estado de los procedimientos administrativos que les afecten. El servidor público responsable de la tramitación del procedimiento estará a disposición del ciudadano interesado para informarle en cada momento de la situación del expediente administrativo.

27.Derecho a ser notificado por escrito o a través de las nuevas tecnologías de las resoluciones que les afecten en el más breve plazo de tiempo posible. El ciudadano tiene derecho a que en breves plazos se pongan en su conocimiento las resoluciones o determinaciones que le afecten en el ejercicio de sus derechos.

28.Derecho a participar en asociaciones o instituciones de usuarios de servicios públicos o de interés general. Los ciudadanos pueden libremente integrarse si así lo desean en gremios o asociaciones con el fin de que sus derechos a buenos servicios a buenos precios tengan adecuada protección.

29.Derecho a actuar en los procedimientos administrativos a través de representante. Allí donde la legislación prevea la existencia de profesionales encargados de la tramitación y seguimiento de expedientes por parte de la ciudadanía, éstos podrán efectivamente hacerse cargo de estas gestiones de manera profesional.

30.Derecho a exigir el cumplimiento de las responsabilidades del personal al servicio de la Administración pública y de los particulares que cumplan funciones administrativas. Los ciudadanos, además del derecho a exigir la justa indemnización por la lesión que puedan 
sufrir en sus bienes o derechos a causa del funcionamiento de los servicios públicos, podrán en cualquier momento demandar las responsabilidades en que puedan haber incurrido determinados servidores públicos en el ejercicio de sus funciones.

31.Derecho a recibir atención especial y preferente si se trata de personas en situación de discapacidad, niños, niñas, adolescentes, mujeres gestantes o adultos mayores, y en general de personas en estado de indefensión o de debilidad manifiesta. Las personas con especiales necesidades serán tratadas por los servidores públicos de forma preferente facilitándoles todo lo posible el acceso a las oficinas públicas así como todos los trámites administrativos que deban realizar.

\section{CONCLUSIONES}

A lo largo de estas páginas, animadas por el propósito de transmitir al lector algunas reflexiones sobre el buen gobierno y la buena administración de instituciones públicas, en su doble modalidad de obligación de los poderes públicos y derecho fundamental de las personas, se ha puesto de relieve la necesidad de subrayar la centralidad del ser humano y de los derechos fundamentales como eje desde el que comprender el sentido de la propia Administración pública. Veamos algunas conclusiones.

En primer lugar, para que pueda hablarse de verdad de una buena Administración pública hay que observar si su actuación se orienta, siempre y en todo, al servicio real de la población, al servicio objetivo del interés general. De un interés general que es concreto y argumentado y que, en última instancia, se dirige a la mejora de las condiciones de vida de las personas.

En segundo término, una buena Administración pública se refleja en la conducta ética de sus miembros. Si los servidores públicos no se distinguen por un trabajo bien hecho, realizado de cara a la comunidad, recto, buscando la justicia y la equidad, entonces no existirá una buena Administración pública.

En tercer lugar, una buena Administración es aquella en la que participan los ciudadanos y desde la que se promueve el ejercicio de la libertad solidaria de las personas.

En cuarto lugar, el derecho fundamental a la Administración pública del que disponemos los ciudadanos define un estatuto jurídico en el que encontramos un repertorio de principios, derechos, también de obligaciones, que caracterizan la posición jurídica central de la persona en sus relaciones con el aparato administrativo.

Finalmente, el derecho fundamental a la buena Administración trae consigo un giro copernicano en la forma de comprender el funcionamiento de la Administración en su conjunto y, sobre todo, en la necesidad de proceder a permanentes procesos de reforma y mejora desde los que la eficacia, la calidad, el servicio y la promoción de las libertades solidarias brillen con luz propia. 


\section{BIBLIOGRAFÍA}

- ARISTÓTELES (1873). Ética a Nicómaco. Madrid: Medina y Navarro editores.

- BONNIN, C.J. (2004). Principios de Administración pública, México: Fondo de Cultura Económica.

- CROzIER, M. (1974). El fenómeno burocrático. Bilbao: Amorrortu.

- FERNÁNDEZ FARRERES, G. (2010). Los códigos de buen gobierno en las administraciones públicas, Administración y ciudadanía Vol. 2, no 2 .

- GARRIDO FALLA, F. (2005). Tratado de Derecho Administrativo. Madrid: Tecnos.

- GARCÍA DE ENTERRÍA, E. y FERNÁNDEZ, TR (2011). Curso de Derecho Administrativo. Madrid: Civitas.

- GARCÍA DE ENTERRÍA, E. (1981). La significación de las libertades públicas para el Derecho Administrativo. Anuario de Derechos Humanos. Madrid: Universidad Complutense.

- GONZÁLEZ NAVARRO, F. (1994). Derecho Administrativo Español. Navarra: Eunsa.

- HABERMAS, J. (2000). Teoría de la acción comunicativa. Barcelona: Paidós Ibérica.

- HABERMAS, J. (2000). Aclaraciones a la ética del discurso. Madrid: Trotta.

- HUME, D. (1992). Historia natural de las religiones. Madrid: Tecnos.

- Llano, A. (1999). Humanismo cívico. Barcelona: Ariel,

- MIR PUIG-PELAT, O. (2002). La responsabilidad patrimonial de la Administración pública. Madrid: Civitas.
- MEMBiEla, L. (2007). la buena administración en la Administración general del Estado. Actualidad administrativa, no 4 .

- MORENO MOLINA, J.A. y MAGÁN, J.M. (2005). La responsabilidad patrimonial de las Administraciones públicas. Madrid: El consultor.

- NIETO, A. (1997). Corrupción en la España contemporánea. Barcelona: Ariel.

- PARDO, M.J. (2004). De la Administración pública a la gobernanza. México: Colegio de México.

- PARADA, R. (2007). Derecho Administrativo. Madrid: Marcial Pons.

- RIFKIN, J. (2010). La sociedad empática. Barcelona: Paidós Ibérica.

- RODRÍGUEZ-ARANA, J. (2012). El poder público y el ciudadano: la buena Administración pública como principio y como derecho. Madrid.

- TOMÁS MALLÉN, B. (2004). El derecho fundamental a la buena administración. Madrid: INAP.

- VILLORIA, M. (2007). La corrupción política. Madrid: Síntesis.

- VON IHERING, R. (2008). La lucha por el derecho. Granada: Comares.

- WEBER, M. (2001). La ética protestante y el espíritu del capitalismo. Madrid: Alianza Editorial. 